\title{
PTEN loss in the continuum of common cancers, rare syndromes and mouse models
}

\author{
M. Christine Hollander, Gideon M. Blumenthal, Phillip A. Dennis \\ Medical Oncology Branch, Center for Cancer Research, National Cancer Institute, 37 Convent \\ Drive Room 1118B, Bethesda, Maryland 20892, USA.
}

\section{Abstract}

$P T E N$ is among the most frequently inactivated tumour suppressor genes in sporadic cancer. PTEN has dual protein and lipid phosphatase activity, and its tumour suppressor activity is dependent on its lipid phosphatase activity, which negatively regulates the PI3K-AKT-mTOR pathway $^{1,2}$. Germline mutations in PTEN have been described in a variety of rare syndromes that are collectively known as the PTEN hamartoma tumour syndromes (PHTS). Cowden syndrome is the best-described syndrome within PHTS, with approximately $80 \%$ of patients having germline PTEN mutations ${ }^{3}$. Patients with Cowden syndrome have an increased incidence of cancers of the breast, thyroid and endometrium, which correspond to sporadic tumour types that commonly exhibit somatic PTEN inactivation. Pten deletion in mice leads to Cowden syndrome-like phenotypes, and tissue-specific Pten deletion has provided clues to the role of PTEN mutation and loss in specific tumour types. Studying PTEN in the continuum of rare syndromes, common cancers and mouse models provides insight into the role of PTEN in tumorigenesis and will inform targeted drug development.

\begin{abstract}
The tumour suppressor PTEN was first identified in 1997 by deletion mapping of brain, breast and prostate cancers ${ }^{4,5}$. Shortly thereafter, germline PTEN mutations were linked to Cowden syndrome ${ }^{6}$ and other proliferative syndromes ${ }^{7}$. The term PTEN hamartoma tumour syndrome (PHTS) is now used to unify these seemingly disparate clinical syndromes into one entity (see the PHTS GeneReview on the US National Library of Medicine website; see Further information). Patients with PHTS are a rare but ideal population to study PTEN biology and targeted drug development, as loss of PTEN function seems to be driving many of the phenotypic features of this syndrome. As is common in most tumours, sporadic (nonhereditary) tumours with somatic PTEN alteration also carry other genetic alterations, making the role of PTEN more ambiguous. As discussed below, mouse models have shown that Pten deletion alone is sufficient to cause tumorigenesis in certain tissues but not in others. However, even when deletion of PTEN alone has minimal effects, it frequently contributes to tumorigenesis in the context of other genetic alterations. Efforts to compensate for loss of Pten by inhibiting the PI3K-AKT-mTOR pathway through genetic or pharmacological means can be investigated in genetically defined mouse models. PHTS
\end{abstract}

Correspondence to P.A.D.pdennis@nih.gov.

Competing interests statement

The authors declare no competing financial interests. 
provides a defined population for clinical trials of pathway-targeted therapies. This Review focuses on tumours types that occur in Cowden syndrome, that exhibit somatic PTEN alterations and that develop in mouse models engineered to lose Pten. The intersection of these three groups provides strong evidence for the functional importance of PTEN alteration in specific tumour types.

\section{PTEN biology}

The PTEN gene spans $105 \mathrm{~kb}$ and includes nine exons on chromosome 10q23. Tumour suppressor function requires both the phosphatase domain and the $\mathrm{C} 2$ or lipid membranebinding domain (FIG. 1), and mutations have been reported throughout the protein. The lipid phosphatase activity of PTEN dephosphorylates the 3-phosphoinositide products of PI3K. 3phosphoinositides can activate important survival kinases, such as phosphoinositidedependent kinase 1 (PDK1; encoded by PDPK1) and AKT, as well as other proteins that are not kinases (FIG. 1). PTEN therefore negatively regulates the AKT pathway, leading to decreased phosphorylation of AKT substrates such as tuberous sclerosis 2 (TSC2) and PRAS40 (encoded by $A K T 1 S 1$ ) that control mTOR activity, p27 (encoded by $C D K N 1 B$ ), p21 (encoded by $C D K N 1 A$ ), glycogen synthase kinase 3 (GSK3A and GSK3B), BCL-2associated agonist of cell death (BAD), apoptosis signal regulating kinase 1 (MAP3K5; also known as ASK1), WT1 regulator PAWR (also known as PAR4) and CHK1, as well as members of the fork-head transcription factor family (for example, FOXO1, FOXO3 and FOXO4 $)^{8}$ and others. Changes in phosphorylation alter the activity and/or localization of these proteins, which in turn affects processes such as cell cycle progression, metabolism, migration, apoptosis, transcription and translation.

Although the lipid phosphatase activity of PTEN is important for its tumour suppressor functions, other functions of PTEN may also prove to be important. For example, several studies have demonstrated that PTEN protein phosphatase activity is important for its functions in cell cycle arrest and inhibition of cell invasion in vitro ${ }^{9-13}$. The lipid phosphatase activity of PTEN is thought to mostly occur at the cell membrane, but PTEN has also demonstrated nuclear functions. The binding of PTEN to centromere protein C1 (CENP-C1) is required for centrosome stability, and its nuclear localization is required for DNA double-strand break (DSB) repair that is mediated by DNA repair protein RAD51 (REF. 14). PTEN also regulates the tumour suppressor function of anaphase-promoting complex (APC) and its regulator E-cadherin (encoded by $\mathrm{CDH} 1$ ) in the nucleus, independently of its lipid phosphatase activity ${ }^{15}$. Altered APC-CDH1 activity has been implicated in multiple tumour types ${ }^{16}$.

\section{PTEN mutations and cancer.}

Germline mutations resulting in the loss of PTEN function or in reduced levels of PTEN are found in approximately $80 \%$ of patients with Cowden syndrome ${ }^{3}$, and PTEN deletion, mutation or alteration occurs in many sporadic tumours ${ }^{17}$. The Sanger Institute maintains a database of PTEN mutations with 1,904 annotated mutations for 30 tumour types (see the Catalogue of Somatic Mutations in Cancer (COSMIC) website; see Further information). From this database, it is clear that in sporadic tumours, mutations, small insertions and 
deletions occur throughout the length of PTEN, although there are higher frequency mutations, known as mutation hotspots, at specific amino acids. However, mutations at these hotspots are not specific for a particular type of cancer. For example, more than 250 different PTEN mutations have been described for endometrial tumours, but 19\% of the 632 reported mutations correspond to Arg130 within the phosphatase catalytic site. Mutations in $\operatorname{Arg} 130$ occur in other tumour types (such as $4 \%$ of central nervous system (CNS) tumours), but they are most frequent in endometrial and ovarian tumours (19\%). Mutant PTEN was reported in $18 \%$ of CNS tumours, with the highest frequency (6\% of PTEN mutations) corresponding to Arg.

Germline PTEN mutations in PHTS are found throughout most of the PTEN coding region, with the exception of exon 9, which encodes the carboxy-terminal 63 amino acids ${ }^{18} ; 40 \%$ occur within exon 5 , which encodes the phosphatase domain ${ }^{18}$. In sporadic tumours, only $2 \%$ of reported sporadic PTEN mutations occur within exon 9 and $27 \%$ occur within exon 5 . Correlations between specific PTEN mutations and disease severity in PHTS have been suggested ${ }^{3,19}$. However, larger data sets and more detailed functional mapping of PTEN will certainly allow more informed models. Allelic or total deletion of PTEN is a frequent occurrence in cancers such as breast and prostate cancer, and melanoma and glioma (see the Tumorscape website; see Further information). A subset of patients with Cowden syndrome carries germline mutations in the PTEN promoter or in potential splice donor and acceptor sites $^{20}$. Splicing alterations can lead to exon skipping that alters PTEN function, but promoter methylation has been shown to decrease apparently normal PTEN ${ }^{21}$. In mice, decreasing PTEN dosage correlates with increasing tumour susceptibility ${ }^{22,23}$. This suggests that reduced levels of normal PTEN are insufficient for its tumour suppressor function and raises the possibility that regulation of PTEN activity could be an important driving mechanism for cancer.

\section{PTEN dosage.}

There are multiple mechanisms for the regulation of PTEN, including transcription, mRNA stability, microRNA (miRNA) targeting, translation and protein stability. PTEN is transcriptionally silenced by promoter methylation in endometrial, gastric, lung, thyroid, breast and ovarian tumours, as well as glioblastoma ${ }^{24-30}$. In glioma, lung and prostate cancer, PTEN expression is decreased by overexpression of miRNA 21 (miR-21), miR-25a, miR-22 or the miR-106b-25 cluster ${ }^{31-33}$. PTEN can also be post-translationally regulated by phosphorylation, ubiquitylation, oxidation, acetylation, proteosomal degradation and subcellular localization (reviewed in REFS 34,35). Although many of these posttranslational changes in PTEN have been shown to alter various cellular phenotypes in vitro, most have not been validated as key regulators of PTEN in human cancer or mouse models. PTEN amino acids Lys13 and Lys289 are monoubiquitylated, which leads to nuclear import in vitro, and Lys 289 mutations have been observed in Cowden syndrome and associated with nuclear exclusion ${ }^{36}$. No Lys 289 mutations have been reported in sporadic cancers, although Lys 13 mutation was found in four of 632 endometrial cancers (see the COSMIC database; see Further information). 


\section{Cancers classically associated with PHTS}

Germline PTEN mutation in Cowden syndrome can lead to decreased or absent expression or activity of the mutant allele. Initial efforts to model Cowden syndrome in mice used genetic deletion of a single allele of Pten, as loss of both alleles is embryonic lethal. These Pten heterozygous $\left(\mathrm{Pten}^{+-}\right)$mice recapitulated some of the neoplastic phenotypes observed in patients with Cowden syndrome, such as breast and endometrial tumours and intestinal polyps ${ }^{37-39}$. However, the genetic background of $\mathrm{Pten}^{+/-}$mice is a strong determinant of susceptibility to specific tumour types (BOX 1). Some strains exhibit tumour types that are not typically associated with Cowden syndrome, such as prostate and adrenal tumours and lymphoma ${ }^{40}$, whereas other strains show a reduced incidence of tumours types that are normally associated with Cowden syndrome, such as breast and endometrial tumours ${ }^{41}$. Decreasing PTEN dosage has been shown to correlate with increasing tumour formation in mice, supporting the value of $\mathrm{Pten}^{+/-}$mice as models for Cowden syndrome.

Somatic PTEN alteration is common in many sporadic tumour types ${ }^{42}$, some of which also occur with germline PTEN alteration in Cowden syndrome (TABLE 1). This suggests that $P T E N$ alteration may be an aetiological factor in these tumour types. Various tissue-specific and/or inducible homozygous deletions of Pten have been generated in mice to model sporadic PTEN loss in tumorigenesis. In the endometrium ${ }^{43}$, mammary gland ${ }^{44}$ and prostate $^{45}$, and in $\mathrm{T}$ cells ${ }^{46}$, homozygous deletion of Pten led to rapid tumour formation in the targeted tissue. Tumours took longer to develop after Pten deletion in the liver ${ }^{47}$, bladder $^{48}$ and lung ${ }^{49}$. By contrast, when Pten was deleted in pancreatic $\beta$-cells ${ }^{50}$ or the intestine $^{51}$, no malignant tumours developed, although intestinal polyps were common, as observed in Cowden syndrome. Loss of other tumour suppressors or the activation of oncogenes can nonetheless combine with PTEN loss to cause cancer in these organs. The following sections describe the intersection of PHTS, sporadic cancer and mouse models to delineate the role of PTEN alteration in specific cancers.

\section{Breast cancer.}

Female patients with Cowden syndrome have a high risk (an estimated 25-50\% risk) of developing breast cancer over the course of their lifetime, and male patients with Cowden syndrome are also thought to be at an increased risk ${ }^{52}$. PTEN loss can also occur in other populations at a high risk of breast cancer, such as those that carry germline mutations in BRCA1 in which PTEN deletions have been described ${ }^{53}$, and can also occur in those at an indeterminate risk. For example, despite the fact that less than $5 \%$ of sporadic breast tumours harbour PTEN mutations, loss of PTEN immunoreactivity is observed in nearly $40 \%{ }^{54}$. This highlights the importance of immunohistochemistry methodology in determining PTEN status ${ }^{55}$. Moreover, about $40 \%$ display loss of heterozygosity (LOH) at 10q23 (REF. 56), and aberrant promoter methylation was identified in nearly $50 \%$ of tumours $^{25}$. As PTEN loss and ERBB2 mutations both activate the AKT signalling pathway, perhaps it is not surprising that many tumours that exhibit loss of PTEN are also oestrogen receptor (ER)-positive and ERBB2-negative ${ }^{54}$.

$\mathrm{Pten}^{+/-}$mice can develop mammary tumours at high frequencies depending on their genetic background ${ }^{39}$. Deletion of both Pten alleles in the mammary epithelium leads to altered 
mammary development and high-frequency, early-onset tumours in mice ${ }^{44}$. Loss of a single Pten allele accelerated tumorigenesis in a Wnt-induced mammary tumour model, and most tumours lost the remaining Pten allele ${ }^{57}$. Similar results were observed when breast-specific Pten deletion was coupled with overexpression of Erbb2 (REF. 58). In two other models, subtle decreases in PTEN expression increased the risk of tumour formation in the absence of any other introduced mutations ${ }^{22,23}$. These mouse studies suggest that decreased PTEN expression leads to an increased risk of breast tumour formation. Attenuated PTEN expression by gene mutation, $\mathrm{LOH}$ or promoter methylation may indeed be a driving alteration in breast cancer, making PTEN signalling pathways or pathways downstream of PTEN potential targets for breast cancer therapy.

\section{Endometrial cancer.}

The lifetime risk of endometrial cancer for patients with Cowden syndrome is estimated to be $5-10 \%{ }^{52,59}$, and $35-50 \%$ of sporadic endometrial carcinomas have PTEN mutations (TABLE 1). Mutations in PTEN are also observed in endometrial hyperplasia, which is thought to be a precursor lesion for endometrial carcinoma ${ }^{60-62}$. Many endometrial tumours have short insertion or deletion frameshift mutations that are typical of microsatellite instability. In particular, PTEN frameshift mutations are observed in endometrial carcinomas that are associated with hereditary non-polyposis colon cancer syndrome (HNPCC) ${ }^{63}$. In addition, polymorphisms in DNA mismatch repair genes affect the risk of endometrial tumours ${ }^{64}$, suggesting that the alterations in PTEN that contribute to endometrial tumours can arise as a result of compromised DNA repair mechanisms. In endometrial tumours, activation of AKT is associated with loss of PTEN ${ }^{65}$.

In mice, loss of Pten is sufficient to cause endometrial carcinogenesis. Depending on strain background, $\mathrm{Pten}^{+/-}$mice can develop endometrial hyperplasia with high penetrance, which in some cases can progress to endometrial carcinoma as the mice age ${ }^{39}$. In this model, most malignant tumours lose the remaining Pten allele ${ }^{39}$, leading to AKT activation and subsequent ERa phosphorylation and activation ${ }^{66}$. Consequently, ER antagonists can substantially decrease hyperplasic lesions and tumour formation in these mice ${ }^{66}$. Likewise, inhibition of mTOR, downstream of PTEN-AKT, can prevent the progression of endometrial hyperplasia ${ }^{67}$.

The role of DNA repair in the maintenance of PTEN integrity is also highlighted in mouse models of endometrial cancer. Familial mutations in the DNA mismatch repair gene $M L H 1$ underlie HNPCC, and deletion of Mlh1 in Pten ${ }^{+/-}$mice accelerated endometrial carcinoma formation $^{68}$. MIh1 deletion was associated with earlier LOH for the remaining Pten allele ${ }^{68}$, suggesting that Pten may be particularly susceptible to disruptions in DNA repair.

\section{Thyroid cancer.}

Thyroid tumours were one of the first tumour types to be associated with Cowden syndrome ${ }^{69}$. Subsequently, about $25 \%$ of benign thyroid adenomas and several sporadic malignant thyroid tumour types were found to have PTENLOH, with PTEN mutations occurring less frequently ${ }^{70,71}$. Complete loss of PTEN expression occurs in less than $10 \%$ of thyroid tumours, but occurs at a higher frequency in the anaplastic subtype ${ }^{72}$. A more recent 
study found methylation of the PTEN promoter in more than 50\% of thyroid tumours of various histologies, particularly follicular carcinoma, and loss of PTEN immunoreactivity correlated significantly with promoter methylation ${ }^{24}$. In addition, PTEN is rearranged in most papillary thyroid carcinomas, and in a subset of normal thyroid samples, leading to putative non-functional PTEN ${ }^{73}$.

Despite the high prevalence of PTEN alterations in human tumours, Pten $^{+/-}$mice only develop thyroid lesions with late onset and low frequency ${ }^{74}$. However, homozygous deletion of Pten in mouse thyroid cells led to the development of goiters and benign follicular adenomas in female mice ${ }^{75}$. Decreased gene dosage of PTEN may nonetheless promote thyroid carcinogenesis, because hemizygous deletion of Pten accelerated thyroid adenocarcinoma formation that was induced by a dominant-negative mutant thyroid hormone receptor- $\beta$, and increased metastases to the lung ${ }^{76}$. In addition, hemizygous deletion of Pten also cooperated with loss of p27 to accelerate thyroid tumorigenesis ${ }^{74}$. These data suggest that Pten mutation alone may not drive thyroid carcinogenesis in mice, but can contribute to the malignant phenotype in the setting of other genetic alterations.

\section{Central nervous system tumours.}

PTEN loss is observed in benign and malignant brain tumours. Lhermitte-Duclos disease is a rare benign tumour (a dysplastic gangliocytoma of the cerebellum) that frequently occurs in patients with Cowden syndrome and is associated with a high rate of morbidity ${ }^{52}$. PTEN LOH occurs in more than $70 \%$ of glioblastomas, with mutation of the remaining PTEN allele found in $44 \% 77$. Decreased PTEN expression is characteristic of tumour progression, as lower grade gliomas express higher levels of PTEN than glioblastomas ${ }^{78,79}$. Independently of tumour grade, higher PTEN expression levels significantly correlated with increased overall survival ${ }^{78}$. miR-26a, which targets PTEN mRNA for degradation, is amplified in glioma and often associated with PTENLOH, suggesting that in this tumour type, multiple mechanisms may coexist to attenuate PTEN expression ${ }^{31}$.

Pten $^{+/-}$mice do not develop brain tumours, but homozygous deletion of Pten in mouse brain resulted in abnormalities that resembled those occurring in patients with Lhermitte-Duclos disease ${ }^{80,81}$. Deletion was associated with an increase in neural stem cells ${ }^{82}$ (BOX 2). Deletion of Pten alone in adult mouse glial cells does not lead to glioma formation, but Pten deletion can contribute to rapid glioma formation in the context of additional genetic alterations. For example, Pten deletion accelerated high-grade malignant astrocytoma formation in the presence of activated HRAS1 (REF. 83), and Pten hemizygosity accelerated astrocytoma formation by SV40 T antigen ${ }^{84}$. Heterozygous deletion of Pten also accelerated glioblastoma formation that is induced by brain-specific heterozygous or homozygous deletion of $\operatorname{Trp} 53$ (REFS 85,86) or heterozygous deletion of both $\operatorname{Trp} 53$ and neurofibromatosis $1(N f 1)^{87}$. Deletion of Pten accelerated glioma progression that is induced by overexpression of platelet-derived growth factor (PDFG). Overexpression of miR-26a also accelerated PDGF-induced glioma and decreased survival. This effect was dependent on PTEN, validating the Pten-targeting role of miR-26a in glioma ${ }^{31}$. 


\section{Pten loss in non-PHTS-associated cancers}

\section{Prostate.}

Prostate tumours have not been associated with Cowden syndrome, perhaps owing to their high incidence in the general population. One of the early cytogenetic abnormalities identified in prostate cancer was the deletion of chromosome $10 \mathrm{q}^{88}$, and nearly a decade later frequent PTEN loss in primary prostate cancer was mapped to this region ${ }^{89}$. Prostate cancer is the most common malignancy in men, and the role of PTEN in prostate tumorigenesis and tumour progression has been extensively studied in mice.

$\mathrm{Pten}^{+/-}$mice develop prostate tumours from 9 months of age ${ }^{74}$. Homozygous deletion of Pten in the mouse prostate led to prostatic intraepithelial neoplasia (PIN) lesions at 6 weeks of age that progressed to invasive and metastatic prostate carcinoma within a few weeks ${ }^{45}$. In this model, prostate tumours responded to androgen ablation, which prolonged survival. However, highly proliferative prostate tumours were observed in these mice at necropsy, suggesting that this is a faithful model of disease progression in humans, in which androgenindependent tumours arise after androgen-ablation therapy ${ }^{90}$.

$\mathrm{Pten}^{+/-}$mice have been crossed with various other strains of genetically engineered mouse (GEM) models that represent the genetic or phenotypic changes that are observed in human prostate cancer. In many cases, concurrent Pten hemizygosity coupled with deletions in other genes accelerates tumorigenesis. For example, concurrent deletion of $C d k n 1 b$, which is often lost in human prostate tumours, accelerated prostate tumorigenesis ${ }^{74}$. Concurrent deletion of the transcription factor $N k \times 3.1$ decreased survival, increased metastasis and resulted in tumours with androgen independence, which is associated with a poor prognosis in patients with prostate cancer ${ }^{91}$. A Tmprss $2-E r g$ translocation, which was recently described in human prostate tumours ${ }^{92}$, in mice can cooperate with Pten hemizygosity to accelerate invasive prostate adenocarcinoma ${ }^{93,94}$. Heterozygous deletion of Pten also accelerated prostate tumorigenesis and decreased survival in the transgenic adenocarcinoma of the mouse prostate (TRAMP) mouse model ${ }^{95}$. The use of Pten hypomorphic alleles demonstrated that decreasing PTEN levels correlate with increased progression of prostate tumours in the mouse ${ }^{96}$, suggesting that Pten may be haploinsufficient for prostate tumorigenesis and/or prostate tumour progression.

\section{Melanoma.}

Despite the fact that melanomas have not been associated with Cowden syndrome, sporadic melanomas frequently have a loss of PTEN through LOH, deletion and mutation ${ }^{97}$. PTEN can also be epigenetically silenced in melanoma, as decreased PTEN transcript levels were associated with PTEN promoter methylation ${ }^{98}$. PTEN methylation also correlated with decreased survival ${ }^{99}$. In another study, low PTEN expression was associated with melanoma ulceration, which is characteristic of aggressive tumours, but did not significantly correlate with overall survival ${ }^{100}$. A link between DNA damage and PTEN mutation in melanoma has been suggested by Wang et al. ${ }^{101}$, who showed that more than $50 \%$ of the melanomas from patients with xeroderma pigmentosum showed PTEN mutation types that are typically associated with ultraviolet radiation exposure ${ }^{101}$. 
In mice, Pten deletion in pigmented mouse cells does not lead to the development of spontaneous melanoma, despite an increase in the number of dermal melanocytes. However, in this model, topical carcinogen treatment led to melanoma formation in nearly $50 \%$ of the mice within 20 weeks $^{102}$. In conjunction with $C d k n 2 a$ (encoding p14ARF) deletion, nearly $10 \%$ of $\mathrm{Pten}^{+/-}$mice developed spontaneous melanoma ${ }^{103}$. Simultaneous activation of BRAF and deletion of Pten in melanocytes leads to early onset spontaneous melanomas, with metastasis to the lymph nodes and lung ${ }^{104}$. Notably, the mTOR inhibitor rapamycin increased survival in these mice by more than twofold ${ }^{104}$. These mouse studies indicate that Pten is probably not a driving mutation in melanoma, but can contribute to a malignant phenotype in the presence of other genetic alterations.

\section{Lung cancer.}

Lung cancer has rarely been described in Cowden syndrome ${ }^{105}$ and somatic PTEN mutations occur at a low frequency in small-cell lung cancer (SCLC) ${ }^{106}$ and non-small-cell lung cancer (NSCLC) ${ }^{107}$. However, other mechanisms to diminish PTEN function may be more important in lung cancer. For example, 24\% of early NSCLC samples lack PTEN expression, which correlated with PTEN promoter methylation ${ }^{30}$. In a later study, PTEN protein expression was reduced or lost in $74 \%$ of lung tumours, and was associated with low or aberrant TP53 staining ${ }^{108}$. Levels of miR-21 were upregulated in lung tumours compared with normal lung tissue in $74 \%$ of cases and were correlated with decreased levels of PTEN mRNA and advanced tumour stage ${ }^{32}$.

PTEN function may determine treatment outcome in lung cancer. Mutant epidermal growth factor receptor $(E G F R)$ is a frequent driving mutation in lung cancer in never-smokers ${ }^{109}$, whose tumours initially respond to treatment with EGFR inhibitors. However, resistant tumours emerge through multiple mechanisms, one of which might be homozygous deletion of $P T E N^{110}$. Regardless of EGFR status, PTEN promoter methylation is significantly associated with poor outcome in surgically treated early stage lung cancer ${ }^{111}$.

$\mathrm{Pten}^{+/-}$mice have not been reported to develop lung tumours. However, lung-specific homozygous deletion of Pten in alveolar type II cells led to lung adenocarcinoma in $87 \%$ of mice at 40-70 weeks of age, and increased both the number and size of urethane-induced lung adenomas ${ }^{49}$. Lung-specific homozygous deletion in bronchiole epithelium cells did not produce tumours in mice, but accelerated tumours driven by mutant Kras, and dramatically decreased survival ${ }^{112}$.

\section{Pancreatic cancer.}

Pancreatic cancer is not associated with Cowden syndrome, and mutations in PTENare rare in sporadic cancers. However, pancreatic tumours frequently have altered localization of PTEN, suggesting that subcellular sequestration of PTEN may decrease its function ${ }^{113}$. In mice, homozygous deletion of Pten in the pancreas leads to metaplasia, which progresses to carcinoma in about $20 \%$ of mice ${ }^{114}$. Pten deletion in pancreatic $\beta$-cells only, does not lead to tumour formation ${ }^{50}$. However, co-deletion of Smad4, the common mediator of signal transduction by transforming growth factor- $\beta$ (TGF $\beta$ ), does lead to tumour formation, which 
is accompanied by increased active AKT and mTOR signalling ${ }^{115}$. These results suggest that PTEN might contribute to pancreatic cancer.

Studies of human cancer and mouse models suggest that alterations in PTEN might have some role in pancreatic tumours ${ }^{113-115}$, liver tumours ${ }^{47,116-119}$, bladder tumours ${ }^{48,120-122}$, adrenal pheochromocytomas ${ }^{123}$, leukaemia ${ }^{124,125}$ and lymphoma ${ }^{40,46,126-128}$. However, in most cases the available human data do not support PTEN as a major factor in these tumour types. Supporting data are included in TABLE 1.

\section{Drug development for PTEN-deficient disorders}

Mouse models of tumorigenesis and diseases such as Cowden syndrome can not only help to discern cause-effect and mutation-disease relationships, but can also be used for preclinical testing and to validate targets for cancer therapy and prevention. For example, deletion of Akt1 in Pten-heterozygous mice prevents endometrial and prostate tumorigenesis, and heterozygous deletion of Mtor or Mlst8 (a component of both mTOR TORC1 and TORC2 complexes) prolongs the life of mice with prostate tumours that are associated with prostatespecific deletion of Pten ${ }^{129,130}$. A hypomorphic mutation in Pdpk1 (REF. 131) and a pharmacological inhibition of mTOR $^{132}$ both prevent the formation of multiple tumour types in $\mathrm{Pten}^{+/-}$mice. These data suggest that inhibitors of pathway components such as AKT1, mTOR or PDK1 might be developed for cancer prevention in or the treatment of patients with germline or tumour-specific PTEN mutations. Inhibitors of mTOR, such as rapamycin (also known as sirolimus) and its analogues, temsirolimus and everolimus, can prevent tumorigenesis in multiple mouse models of cancer. For example, everolimus reduced the progression of endometrial hyperplasia, and sirolimus reversed premalignant lesions and/or decreased proliferation in prostate tumours in $\mathrm{Pten}^{+/-}$mice ${ }^{67,133}$. Metformin, an activator of AMP-activated protein kinase (AMPK) that leads to inactivation of mTOR, delayed tumour onset in $\mathrm{Pten}^{+/-}$mice ${ }^{134}$.

Several compounds that have been designed to inhibit the PI3K-AKT-mTOR pathway in cancer are in clinical development, including newer mTOR inhibitors that target the ATPbinding domain. Some of these have cross-reactivity with class I PI3Ks and other proteins with PI3K domains (TABLE 2). These pathway inhibitors may be useful in the prevention of malignancy or in treating existing tumours. Patients with germline mutations of PTEN could be an ideal population to test these inhibitors, as pathway activation is a feature of both benign and malignant tumours in Cowden syndrome. Easily accessible benign tumours in the skin and gastrointestinal tract of patients with Cowden syndrome could provide in vivo evidence of target modulation and be a reliable surrogate for cancer cells.

Of all of the pathway inhibitors in development, inhibitors of the TORC1 complex, such as sirolimus and its analogues, are the most developed and have established safety profiles that are most relevant for rare syndromes. For example, sirolimus was tested in a Phase II trial of patients with tuberous sclerosis, which, like Cowden syndrome, is a highly morbid familial syndrome in which the loss of a tumour suppressor gene leads to mTOR activation ${ }^{135}$. In patients with tuberous sclerosis, prolonged use of sirolimus seemed to be safe and showed preliminary efficacy in shrinking angiomyolipomas and improving pulmonary function ${ }^{135}$. 
Treatment with everolimus similarly caused a sustained decrease in subependymal giant-cell astrocytomas (SEGAs) in patients with tuberous sclerosis ${ }^{136}$. A case report also showed that sirolimus decreased tumour burden in a child with Proteus syndrome and a germline PTEN mutation ${ }^{137}$. Sirolimus is currently being tested in patients with Cowden syndrome (clinical trial number: ).

In cancer, temsirolimus and everolimus are approved for the treatment of advanced renal cell carcinoma, and are being tested as single agents, and in combination, in various other malignancies. The activity of rapamycin analogues as single agents in common cancers has been modest, however, which could be related to feedback activation of AKT through insulin receptor substrate 1 (IRS1) or through direct phosphorylation at Ser473 by TORC2 (REF. 138) (FIG. 2). Feedback activation of AKT has been observed in $P T E N$-null glioblastoma biopsy samples from patients treated with sirolimus, and was associated with a shorter time to disease progression. Nonetheless, the modest results of clinical trials with TORC1 inhibitors in cancers in which PTEN inactivation is common suggest that the inhibition of TORC1 alone is insufficient to induce meaningful tumour regression ${ }^{139,140 .}$

The next generation of pathway inhibitors includes dual PI3K-mTOR inhibitors, PI3K inhibitors, AKT inhibitors and mTOR complex catalytic site inhibitors (reviewed in REFS 141-143). These compounds may better compensate for the loss of PTEN by targeting more upstream components of the pathway and may circumvent feedback AKT activation. However, these agents are likely to be more toxic than the pure TORC1 inhibitors and are also likely to be less useful for cancer prevention in patients with rare syndromes.

\section{Trial design considerations for PHTS and PTEN-deficient cancers.}

Given the rarity of Cowden syndrome, cancer prevention trials pose a challenge. Pilot studies using pathway inhibitors that focus on tissues at risk for malignant transformation are more feasible. For example, a trial evaluating the effects of a pathway inhibitor on endometrial hyperplasia or fibrocystic changes of the breast in patients with Cowden syndrome would be a useful proof-of-concept, but this would require multiple biopsies, which might be objectionable to patients with Cowden syndrome who do not have cancer. Molecular imaging to assess tumour metabolism using fluorodeoxyglucose (FDG)-positron emission tomography (PET) or tumour cell proliferation using deoxyfluorothymidine (FLT)-PET might be useful surrogates for patients with Cowden syndrome who are unwilling or unable to undergo biopsies. Trials in patients with Cowden syndrome could also test pathway inhibitors as a means of ameliorating the severe but non-malignant manifestations of the disease, such as Lhermitte-Duclos disease, in which improvement in neurological function could be measured clinically. Selecting objective and reliable clinical end points for these studies is challenging, but pharmacodynamic end points and assays that are validated in trials of patients with Cowden syndrome could be applied to general oncology trials.

The location of PTEN mutations or relevant epigenetic modifications may assist the choice of therapy for $P T E N$-deficient malignancies. For example, if mutations occur in the Cterminal PEST domain and spare the phosphatase domain, treatment with a proteasome inhibitor might rescue PTEN from degradation. Moreover, treatment with statins might 
increase the expression of PTEN through peroxisome proliferator-activated receptor- $\gamma$ (PPARG)-mediated promoter activation ${ }^{144}$, and demethylating agents or histone deacetylase inhibitors might reverse epigenetic silencing. Three recent studies suggest that PTEN is required for homologous recombination, which could be exploited therapeutically. In one mouse study, T cell-specific Pten deletion resulted in lymphomas with T cell receptor (Tcr)$M y c$ translocations resulting from aberrant Tcr recombination ${ }^{145}$. In PTEN-deficient endometrial cancer cell lines, decreased homologous recombination underlies sensitivity to polyadenosine diphosphate ribose polymerase (PARP) inhibitors ${ }^{146}$. Pten deletion decreased homologous recombination in mouse astrocytes through the downregulation of the DNA repair protein RAD51. These studies raise the possibility that PARP inhibitors may have efficacy for PTEN-deficient tumours ${ }^{147}$, owing to generalized defects in homologous recombination.

As PTEN loss mediates resistance to targeted therapies against receptor tyrosine kinases, combinations of PI3K or AKT inhibitors with cell surface receptor inhibitors might be effective. For example, acquired resistance to EGFR tyrosine kinase inhibitors in lung cancer and trastuzumab in ERBB2-amplified breast cancer are associated with Pten loss and/or maintenance of AKT activation ${ }^{110,148,149}$. Inhibition of multiple nodes of the signalling cascade may effectively overcome acquired resistance. Alternatively, targeting of parallel networks by targeting the PI3K-AKT pathway and the MEK-ERK (MAPK1, MAPK3 and MAPK1) pathway may also overcome acquired resistance, have antitumour activity and ultimately accelerate the development of these agents to treat patients with germline or somatic loss of PTEN.

\section{Perspectives and conclusions}

The comparison of sporadic tumours carrying PTEN alteration, tumours that occur with germline PTEN mutation in Cowden syndrome, and tumours that develop in Pten-deficient GEM strains provides evidence that the development of many different tumour types seems to be driven by the loss of PTEN function. mTOR inhibitors have been approved for the treatment of advanced renal cell carcinoma and SEGA that is associated with tuberous sclerosis. Upstream pathway inhibitors of PI3K and AKT are in clinical development, both in combination with traditional chemotherapy and with inhibitors of parallel pathways such as MEK-ERK. This is a reasonable approach as PTEN mutations and subsequent activation of the AKT-mTOR pathway provide survival signals that are associated with resistance to therapy. However, one key question that remains to be answered is whether tumours that develop as a consequence of PTEN attenuation are addicted to that signal. Given that PTEN alteration is so prevalent in many human tumour types, validating PTEN as a target during different stages of tumorigenesis is crucial to validating any downstream targets. Mouse models could be used to show whether re-expression of Pten in Pten-deficient tumours leads to tumour regression, as is the case for Trp53-null lymphomas and sarcomas upon Trp53 reexpression ${ }^{150}$, or whether it is context-dependent as is the case for the reconstitution of Trp53 in lung tumours ${ }^{151,152}$. Identification of novel PTEN functions and crucial signalling events downstream of PTEN could provide additional targets and new therapeutic approaches. 
It is becoming clear that PTEN may have many important functions, any or all of which might contribute to its tumour suppressor activity. Pten deletion clearly contributes to tumorigenesis in multiple tissues in mice. The continued characterization of specific human PTEN mutations is driving the discovery of novel PTEN functions that might correlate with specific tumour risk in Cowden syndrome and might have implications for sporadic tumours.

\section{Acknowledgements}

This Review is dedicated to T.S., a dear patient with Cowden syndrome. The authors remain devoted to the study and cure of Cowden syndrome in her honour and the honour of others who wrestle with the consequences of disease caused by the loss of PTEN.

\section{References}

1. Stambolic V et al. Negative regulation of PKB/Akt-dependent cell survival by the tumor suppressor PTEN. Cell 95, 29-39 (1998). [PubMed: 9778245]

2. Wu X, Senechal K, Neshat MS, Whang YE \& Sawyers CL The PTEN/MMAC1 tumor suppressor phosphatase functions as a negative regulator of the phosphoinositide 3-kinase/Akt pathway. Proc. Natl Acad. Sci. USA 95, 15587-15591 (1998). [PubMed: 9861013]

3. Marsh DJ et al. Mutation spectrum and genotype-phenotype analyses in Cowden disease and Bannayan-Zonana syndrome, two hamartoma syndromes with germline PTEN mutation. Hum. Mol. Genet 7, 507-515 (1998). [PubMed: 9467011]

4. Li J et al. PTEN, a putative protein tyrosine phosphatase gene mutated in human brain, breast, and prostate cancer. Science 275, 1943-1947 (1997). [PubMed: 9072974]

5. Steck PA et al. Identification of a candidate tumour suppressor gene, MMAC1, at chromosome 10q23.3 that is mutated in multiple advanced cancers. Nature Genet. 15, 356-362 (1997). [PubMed: 9090379]

6. Liaw D et al. Germline mutations of the PTEN gene in Cowden disease, an inherited breast and thyroid cancer syndrome. Nature Genet. 16, 64-67 (1997). [PubMed: 9140396]

7. Hobert JA \& Eng C PTEN hamartoma tumor syndrome: an overview. Genet. Med 11, 687-694 (2009). [PubMed: 19668082]

8. Manning B \& Cantley L AKT/PKB signaling: navigating downstream. Cell 129, 1261-1274 (2007). [PubMed: 17604717]

9. Hlobilkova A et al. Cell cycle arrest by the PTEN tumor suppressor is target cell specific and may require protein phosphatase activity. Exp. Cell Res. 256, 571-577 (2000). [PubMed: 10772829]

10. Weng LP, Brown JL \& Eng., C. PTEN coordinates $\mathrm{G}_{1}$ arrest by down-regulating cyclin D1 via its protein phosphatase activity and up-regulating p27 via its lipid phosphatase activity in a breast cancer model. Hum. Mol. Genet 10, 599-604 (2001). [PubMed: 11230179]

11. Dey $\mathrm{N}$ et al. The protein phosphatase activity of PTEN regulates SRC family kinases and controls glioma migration. Cancer Res. 68, 1862-1871 (2008). [PubMed: 18339867]

12. Davidson L et al. Suppression of cellular proliferation and invasion by the concerted lipid and protein phosphatase activities of PTEN. Oncogene 29, 687-697 (2010). [PubMed: 19915616]

13. Poon JS, Eves R \& Mak AS Both lipid- and protein-phosphatase activities of PTEN contribute to the p53-PTEN anti-invasion pathway. Cell Cycle 9, 4450-4454 (2010). [PubMed: 21084866]

14. Shen WH et al. Essential role for nuclear PTEN in maintaining chromosomal integrity. Cell 128, 157-170 (2007). [PubMed: 17218262]

15. Song MS et al. Nuclear PTEN regulates the APC-CDH1 tumor-suppressive complex in a phosphatase-independent manner. Cell 144, 187-199 (2011). [PubMed: 21241890]

16. Qiao X, Zhang L, Gamper AM, Fujita T \& Wan Y APC/C-Cdh1: from cell cycle to cellular differentiation and genomic integrity. Cell Cycle 9, 3904-3912 (2010). [PubMed: 20935501]

17. Chalhoub N \& Baker SJ PTEN and the PI3-kinase pathway in cancer. Annu. Rev. Pathol 4, $127-$ 150 (2009). [PubMed: 18767981] 
18. Orloff MS \& Eng C Genetic and phenotypic heterogeneity in the PTEN hamartoma tumour syndrome. Oncogene 27, 5387-5397 (2008). [PubMed: 18794875]

19. Marsh DJ et al. PTEN mutation spectrum and genotype-phenotype correlations in Bannayan-RileyRuvalcaba syndrome suggest a single entity with Cowden syndrome. Hum. Mol. Genet 8, 14611472 (1999). [PubMed: 10400993]

20. Pezzolesi MG et al. Mutation-positive and mutation-negative patients with Cowden and BannayanRiley-Ruvalcaba syndromes associated with distinct 10q haplotypes. Am. J. Hum. Genet 79, 923934 (2006). [PubMed: 17033968]

21. Zhou XP et al. Germline PTEN promoter mutations and deletions in Cowden/Bannayan-RileyRuvalcaba syndrome result in aberrant PTEN protein and dysregulation of the phosphoinositol-3kinase/Akt pathway. Am. J. Hum. Genet 73, 404-411 (2003). [PubMed: 12844284]

22. Alimonti A et al. Subtle variations in Pten dose determine cancer susceptibility. Nature Genet. 42, 454-458 (2010). [PubMed: 20400965]

23. Shen-Li H, Koujak S, Szablocs M \& Parsons R Reduction of Pten dose leads to neoplastic development in multiple organs of Pten ${ }^{\text {shRNA }}$ mice. Cancer Biol. Ther 10, 1194-1200 (2010). [PubMed: 20980828]

24. Alvarez-Nunez F et al. PTEN promoter methylation in sporadic thyroid carcinomas. Thyroid 16, 17-23 (2006). [PubMed: 16487009]

25. Garcia JM et al. Promoter methylation of the PTEN gene is a common molecular change in breast cancer. Genes Chromosom. Cancer 41, 117-124 (2004).

26. Ho CM et al. PTEN promoter methylation and LOH of 10q22-23 locus in PTEN expression of ovarian clear cell adenocarcinomas. Gynecol. Oncol 112, 307-313 (2009). [PubMed: 19007975]

27. Kang YH, Lee HS \& Kim WH Promoter methylation and silencing of PTEN in gastric carcinoma. Lab. Invest 82, 285-291 (2002). [PubMed: 11896207]

28. Koul D PTEN signaling pathways in glioblastoma. Cancer Biol. Ther 7, 1321-1325 (2008). [PubMed: 18836294]

29. Salvesen HB et al. PTEN methylation is associated with advanced stage and microsatellite instability in endometrial carcinoma. Int. J. Cancer 91, 22-26 (2001). [PubMed: 11149415]

30. Soria $\mathrm{J}$ et al. Lack of PTEN expression in non-small cell lung cancer could be related to promoter methylation. Clin. Cancer Res. 8, 1178-1184 (2002). [PubMed: 12006535]

31. Huse JT et al. The PTEN-regulating microRNA miR-26a is amplified in high-grade glioma and facilitates gliomagenesis in vivo. Genes Dev. 23, 1327-1337 (2009). [PubMed: 19487573]

32. Zhang JG et al. MicroRNA-21 (miR-21) represses tumor suppressor PTEN and promotes growth and invasion in non-small cell lung cancer (NSCLC). Clin. Chim. Acta 411, 846-852 (2010). [PubMed: 20223231]

33. Poliseno L et al. Identification of the miR-106b $\sim 25$ microRNA cluster as a proto-oncogenic PTEN-targeting intron that cooperates with its host gene MCM7 in transformation. Sci. Signal 3, ra29 (2010). [PubMed: 20388916]

34. Tamguney T \& Stokoe D New insights into PTEN. J. Cell Sci. 120, 4071-4079 (2007). [PubMed: 18032782]

35. Wang X \& Jiang X Post-translational regulation of PTEN. Oncogene 27, 5454-5463 (2008). [PubMed: 18794880]

36. Trotman LC et al. Ubiquitination regulates PTEN nuclear import and tumor suppression. Cell 128, 141-156 (2007). [PubMed: 17218261]

37. Di Cristofano A, Pesce B, Cordon-Cardo C \& Pandolfi PP Pten is essential for embryonic development and tumour suppression. Nature Genet. 19, 348-355 (1998). [PubMed: 9697695]

38. Podsypanina K et al. Mutation of Pten/Mmac1 in mice causes neoplasia in multiple organ systems. Proc. Natl Acad. Sci. USA 96, 1563-1568 (1999). [PubMed: 9990064]

39. Stambolic V et al. High incidence of breast and endometrial neoplasia resembling human Cowden

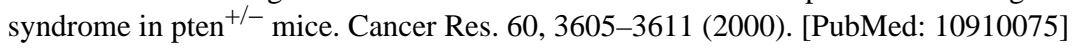

40. Suzuki A et al. High cancer susceptibility and embryonic lethality associated with mutation of the PTEN tumor suppressor gene in mice. Curr. Biol 8, 1169-1178 (1998). [PubMed: 9799734] 
41. Hollander MC et al. Strain-specific spontaneous and NNK-mediated tumorigenesis in Pten+/mice. Neoplasia 10, 866-872 (2008). [PubMed: 18683321]

42. Keniry M \& Parsons R The role of PTEN signaling perturbations in cancer and in targeted therapy. Oncogene 27, 5477-5485 (2008). [PubMed: 18794882]

43. Daikoku T et al. Conditional loss of uterine Pten unfailingly and rapidly induces endometrial cancer in mice. Cancer Res. 68, 5619-5627 (2008). [PubMed: 18632614]

44. Li G et al. Conditional loss of PTEN leads to precocious development and neoplasia in the mammary gland. Development 129, 4159-4170 (2002). [PubMed: 12163417]

45. Wang S et al. Prostate-specific deletion of the murine Pten tumor suppressor gene leads to metastatic prostate cancer. Cancer Cell 4, 209-221 (2003). [PubMed: 14522255]

46. Suzuki A et al. T cell-specific loss of Pten leads to defects in central and peripheral tolerance. Immunity 14, 523-534 (2001). [PubMed: 11371355]

47. Horie Y et al. Hepatocyte-specific Pten deficiency results in steatohepatitis and hepatocellular carcinomas. J. Clin. Invest 113, 1774-1783 (2004). [PubMed: 15199412]

48. Tsuruta $\mathrm{H}$ et al. Hyperplasia and carcinomas in Pten-deficient mice and reduced PTEN protein in human bladder cancer patients. Cancer Res. 66, 8389-8396 (2006). [PubMed: 16951148]

49. Yanagi $\mathrm{S}$ et al. Pten controls lung morphogenesis, bronchioalveolar stem cells, and onset of lung adenocarcinomas in mice. J. Clin. Invest 117, 2929-2940 (2007). [PubMed: 17909629]

50. Stiles BL et al. Selective deletion of Pten in pancreatic $\beta$ cells leads to increased islet mass and resistance to STZ-induced diabetes. Mol. Cell. Biol 26, 2772-2781 (2006). [PubMed: 16537919]

51. Marsh V et al. Epithelial Pten is dispensable for intestinal homeostasis but suppresses adenoma development and progression after Apc mutation. Nature Genet. 40, 1436-1444 (2008). [PubMed: 19011632]

52. Gustafson S, Zbuk KM, Scacheri C \& Eng C Cowden syndrome. Semin. Oncol 34, 428-434 (2007). [PubMed: 17920899]

53. Saal LH et al. Recurrent gross mutations of the PTEN tumor suppressor gene in breast cancers with deficient DSB repair. Nature Genet. 40, 102-107 (2008). [PubMed: 18066063]

54. Perez-Tenorio $\mathrm{G}$ et al. PIK3CA mutations and PTEN loss correlate with similar prognostic factors and are not mutually exclusive in breast cancer. Clin. Cancer Res. 13, 3577-3584 (2007). [PubMed: 17575221]

55. Sangale $\mathrm{Z}$ et al. A robust immunohistochemical assay for detecting PTEN expression in human tumors. Appl. Immunohistochem. Mol. Morphol 19, 173-183 (2011).

56. Singh B, Ittmann MM \& Krolewski JJ Sporadic breast cancers exhibit loss of heterozygosity on chromosome segment 10q23 close to the Cowden disease locus. Genes Chromosom. Cancer 21, 166-171 (1998). [PubMed: 9491329]

57. Li Y et al. Deficiency of Pten accelerates mammary oncogenesis in MMTV-Wnt-1 transgenic mice. BMC Mol. Biol 2, 2 (2001). [PubMed: 11178110]

58. Schade B et al. PTEN deficiency in a luminal ErbB-2 mouse model results in dramatic acceleration of mammary tumorigenesis and metastasis. J. Biol. Chem 284, 19018-19026 (2009). [PubMed: 19435886]

59. Blumenthal GM \& Dennis PA PTEN hamartoma tumor syndromes. Eur. J. Hum. Genet 16, 12891300 (2008). [PubMed: 18781191]

60. Risinger JI, Hayes AK, Berchuck A \& Barrett JC PTEN/MMAC1 mutations in endometrial cancers. Cancer Res. 57, 4736-4738 (1997). [PubMed: 9354433]

61. Maxwell GL et al. Mutation of the PTEN tumor suppressor gene in endometrial hyperplasias. Cancer Res. 58, 2500-2503 (1998). [PubMed: 9635567]

62. Tashiro $\mathrm{H}$ et al. Mutations in PTEN are frequent in endometrial carcinoma but rare in other common gynecological malignancies. Cancer Res. 57, 3935-3940 (1997). [PubMed: 9307275]

63. Zhou XP, Kuismanen S, Nystrom-Lahti M, Peltomaki P \& Eng., C. Distinct PTEN mutational spectra in hereditary non-polyposis colon cancer syndrome-related endometrial carcinomas compared to sporadic microsatellite unstable tumors. Hum. Mol. Genet 11, 445-450 (2002). [PubMed: 11854177] 
64. Beiner ME et al. Endometrial cancer risk is associated with variants of the mismatch repair genes MLH1 and MSH2. Cancer Epidemiol. Biomarkers Prev. 15, 1636-1640 (2006). [PubMed: 16985024]

65. Kanamori Y et al. Correlation between loss of PTEN expression and Akt phosphorylation in endometrial carcinoma. Clin. Cancer Res. 7, 892-895 (2001). [PubMed: 11309338]

66. Vilgelm A et al. Akt-mediated phosphorylation and activation of estrogen receptor $\mathrm{a}$ is required for endometrial neoplastic transformation in Pten $^{+/-}$mice. Cancer Res. 66, 3375-3380 (2006). [PubMed: 16585156]

67. Milam MR et al. Reduced progression of endometrial hyperplasia with oral mTOR inhibition in the Pten heterozygote murine model. Am. J. Obstet. Gynecol 196, 247 (2007). [PubMed: 17346540]

68. Wang $\mathrm{H}$ et al. DNA mismatch repair deficiency accelerates endometrial tumorigenesis in Pten heterozygous mice. Am. J. Pathol 160, 1481-1486 (2002). [PubMed: 11943731]

69. Lloyd KM \& Dennis M Cowden's disease. A possible new symptom complex with multiple system involvement. Ann. Intern. Med 58, 136-142 (1963). [PubMed: 13931122]

70. Dahia PL et al. Somatic deletions and mutations in the Cowden disease gene, PTEN, in sporadic thyroid tumors. Cancer Res. 57, 4710-4713 (1997). [PubMed: 9354427]

71. Halachmi N et al. Somatic mutations of the PTEN tumor suppressor gene in sporadic follicular thyroid tumors. Genes Chromosom. Cancer 23, 239-243 (1998).

72. Frisk T et al. Silencing of the PTEN tumor-suppressor gene in anaplastic thyroid cancer. Genes Chromosom. Cancer 35, 74-80 (2002).

73. Puxeddu E et al. Characterization of novel non-clonal intrachromosomal rearrangements between the H4 and PTEN genes (H4/PTEN) in human thyroid cell lines and papillary thyroid cancer specimens. Mutat. Res 570, 17-32 (2005). [PubMed: 15680400]

74. Di Cristofano A, De Acetis M, Koff A, Cordon-Cardo C \& Pandolfi PP Pten and p27KIP1 cooperate in prostate cancer tumor suppression in the mouse. Nature Genet. 27, 222-224 (2001). [PubMed: 11175795]

75. Yeager N, Klein-Szanto A, Kimura S \& Di Cristofano A Pten loss in the mouse thyroid causes goiter and follicular adenomas: insights into thyroid function and Cowden disease pathogenesis. Cancer Res. 67, 959-966 (2007). [PubMed: 17283127]

76. Guigon CJ, Zhao L, Willingham MC \& Cheng SY PTEN deficiency accelerates tumour progression in a mouse model of thyroid cancer. Oncogene 28, 509-517 (2009). [PubMed: 18997818]

77. Wang SI et al. Somatic mutations of PTEN in glioblastoma multiforme. Cancer Res. 57, 41834186 (1997). [PubMed: 9331071]

78. Sano T et al. Differential expression of MMAC/PTEN in glioblastoma multiforme: relationship to localization and prognosis. Cancer Res. 59, 1820-1824 (1999). [PubMed: 10213484]

79. Schmidt EE et al. Mutational profile of the PTEN gene in primary human astrocytic tumors and cultivated xenografts. J. Neuropathol. Exp. Neurol 58, 1170-1183 (1999). [PubMed: 10560660]

80. Kwon $\mathrm{CH}$ et al. Pten regulates neuronal soma size: a mouse model of Lhermitte-Duclos disease. Nature Genet. 29, 404-411 (2001). [PubMed: 11726927]

81. Backman SA et al. Deletion of Pten in mouse brain causes seizures, ataxia and defects in soma size resembling Lhermitte-Duclos disease. Nature Genet. 29, 396-403 (2001). [PubMed: 11726926]

82. Groszer $M$ et al. PTEN negatively regulates neural stem cell self-renewal by modulating G0-G1 cell cycle entry. Proc. Natl Acad. Sci. USA 103, 111-116 (2006). [PubMed: 16373498]

83. Wei Q et al. High-grade glioma formation results from postnatal pten loss or mutant epidermal growth factor receptor expression in a transgenic mouse glioma model. Cancer Res. 66, 74297437 (2006). [PubMed: 16885338]

84. Xiao A, Wu H, Pandolfi PP, Louis DN \& Van Dyke T Astrocyte inactivation of the pRb pathway predisposes mice to malignant astrocytoma development that is accelerated by PTEN mutation. Cancer Cell 1, 157-168 (2002). [PubMed: 12086874]

85. Zheng $\mathrm{H}$ et al. p53 and Pten control neural and glioma stem/progenitor cell renewal and differentiation. Nature 455, 1129-1133 (2008). [PubMed: 18948956] 
86. Zheng $\mathrm{H}$ et al. Pten and p53 converge on c-Myc to control differentiation, self-renewal, and transformation of normal and neoplastic stem cells in glioblastoma. Cold Spring Harb. Symp. Quant. Biol 73, 427-437 (2008). [PubMed: 19150964]

87. Kwon $\mathrm{CH}$ et al. Pten haploinsufficiency accelerates formation of high-grade astrocytomas. Cancer Res. 68, 3286-3294 (2008). [PubMed: 18451155]

88. Lundgren R, Kristoffersson U, Heim S, Mandahl N \& Mitelman F Multiple structural chromosome rearrangements, including $\operatorname{del}(7 \mathrm{q})$ and $\operatorname{del}(10 \mathrm{q})$, in an adenocarcinoma of the prostate. Cancer Genet. Cytogenet 35, 103-108 (1988). [PubMed: 3180000]

89. Cairns $\mathrm{P}$ et al. Frequent inactivation of PTEN/MMAC1 in primary prostate cancer. Cancer Res. 57, 4997-5000 (1997). [PubMed: 9371490]

90. Feldman BJ \& Feldman D The development of androgen-independent prostate cancer. Nature Rev. Cancer 1, 34-45 (2001). [PubMed: 11900250]

91. Abate-Shen $\mathrm{C}$ et al. Nkx3.1; Pten mutant mice develop invasive prostate adenocarcinoma and lymph node metastases. Cancer Res. 63, 3886-3890 (2003). [PubMed: 12873978]

92. Varambally $\mathrm{S}$ et al. Integrative genomic and proteomic analysis of prostate cancer reveals signatures of metastatic progression. Cancer Cell 8, 393-406 (2005). [PubMed: 16286247]

93. King JC et al. Cooperativity of TMPRSS2-ERG with PI3-kinase pathway activation in prostate oncogenesis. Nature Genet. 41, 524-526 (2009). [PubMed: 19396167]

94. Carver BS et al. Aberrant ERG expression cooperates with loss of PTEN to promote cancer progression in the prostate. Nature Genet. 41, 619-624 (2009). [PubMed: 19396168]

95. Kwabi-Addo B et al. Haploinsufficiency of the Pten tumor suppressor gene promotes prostate cancer progression. Proc. Natl Acad. Sci. USA 98, 11563-11568 (2001). [PubMed: 11553783]

96. Trotman LC et al. Pten dose dictates cancer progression in the prostate. PLoS Biol. 1, e59 (2003). [PubMed: 14691534]

97. Guldberg P et al. Disruption of the MMAC1/PTEN gene by deletion or mutation is a frequent event in malignant melanoma. Cancer Res. 57, 3660-3663 (1997). [PubMed: 9288767]

98. Mirmohammadsadegh A et al. Epigenetic silencing of the PTEN gene in melanoma. Cancer Res. 66, 6546-6552 (2006). [PubMed: 16818626]

99. Lahtz C, Stranzenbach R, Fiedler E, Helmbold P \& Dammann RH Methylation of PTEN as a prognostic factor in malignant melanoma of the skin. J. Invest. Dermatol 130, 620-622 (2010). [PubMed: 19798057]

100. Mikhail M et al. PTEN expression in melanoma: relationship with patient survival, Bcl-2 expression, and proliferation. Clin. Cancer Res. 11, 5153-5157 (2005). [PubMed: 16033830]

101. Wang Y et al. Evidence of ultraviolet type mutations in xeroderma pigmentosum melanomas. Proc. Natl Acad. Sci. USA 106, 6279-6284 (2009). [PubMed: 19329485]

102. Inoue-Narita $T$ et al. Pten deficiency in melanocytes results in resistance to hair graying and susceptibility to carcinogen-induced melanomagenesis. Cancer Res. 68, 5760-5768 (2008). [PubMed: 18632629]

103. You MJ et al. Genetic analysis of Pten and Ink4a/Arf interactions in the suppression of tumorigenesis in mice. Proc. Natl Acad. Sci. USA 99, 1455-1460 (2002). [PubMed: 11818530]

104. Dankort D et al. Braf(V600E) cooperates with Pten loss to induce metastatic melanoma. Nature Genet. 41, 544-552 (2009). [PubMed: 19282848]

105. Scheper MA, Nikitakis NG, Sarlani E, Sauk JJ \& Meiller TF Cowden syndrome: report of a case with immunohistochemical analysis and review of the literature. Oral Surg. Oral Med. Oral Pathol. Oral Radiol. Endod 101, 625-631 (2006). [PubMed: 16632275]

106. Yokomizo A et al. PTEN/MMAC1 mutations identified in small cell, but not in non-small cell lung cancers. Oncogene 17, 475-479 (1998). [PubMed: 9696041]

107. Kohno T, Takahashi M, Manda R \& Yokota J Inactivation of the PTEN/MMAC1/TEP1 gene in human lung cancers. Genes Chromosom. Cancer 22, 152-156 (1998). [PubMed: 9598803]

108. Marsit CJ et al. PTEN expression in non-small-cell lung cancer: evaluating its relation to tumor characteristics, allelic loss, and epigenetic alteration. Hum. Pathol 36, 768-776 (2005). [PubMed: 16084946] 
109. Gazdar AF Activating and resistance mutations of EGFR in non-small-cell lung cancer: role in clinical response to EGFR tyrosine kinase inhibitors. Oncogene Suppl. 28, S24-S31 (2009).

110. Sos ML et al. PTEN loss contributes to erlotinib resistance in EGFR-mutant lung cancer by activation of Akt and EGFR. Cancer Res. 69, 3256-3261 (2009). [PubMed: 19351834]

111. Buckingham L et al. PTEN, RASSF1 and DAPK sitespecific hypermethylation and outcome in surgically treated stage I and II nonsmall cell lung cancer patients. Int. J. Cancer 126, 1630-1639 (2010). [PubMed: 19795445]

112. Iwanaga $\mathrm{K}$ et al. Pten inactivation accelerates oncogenic K-ras-initiated tumorigenesis in a mouse model of lung cancer. Cancer Res. 68, 1119-1127 (2008). [PubMed: 18281487]

113. Perren A et al. Mutation and expression analyses reveal differential subcellular compartmentalization of PTEN in endocrine pancreatic tumors compared to normal islet cells. Am. J. Pathol 157, 1097-1103 (2000). [PubMed: 11021813]

114. Stanger BZ et al. Pten constrains centroacinar cell expansion and malignant transformation in the pancreas. Cancer Cell 8, 185-195 (2005). [PubMed: 16169464]

115. Xu X, Ehdaie B, Ohara N, Yoshino T \& Deng CX Synergistic action of Smad4 and Pten in suppressing pancreatic ductal adenocarcinoma formation in mice. Oncogene 29, 674-686 (2010). [PubMed: 19901970]

116. Yao YJ et al. PTEN/MMAC1 mutations in hepatocellular carcinomas. Oncogene 18, 3181-3185 (1999). [PubMed: 10340391]

117. Yeh KT et al. Mutation analysis of the putative tumor suppressor gene PTEN/MMAC1 in hepatocellular carcinoma. Cancer Invest. 18, 123-129 (2000). [PubMed: 10705874]

118. Dong-Dong L, Xi-Ran Z \& Xiang-Rong C Expression and significance of new tumor suppressor gene PTEN in primary liver cancer. J. Cell. Mol. Med 7, 67-71 (2003). [PubMed: 12767263]

119. Stiles B et al. Liver-specific deletion of negative regulator Pten results in fatty liver and insulin hypersensitivity [corrected]. Proc. Natl Acad. Sci. USA 101, 2082-2087 (2004). [PubMed: 14769918]

120. Cairns P et al. Point mutation and homozygous deletion of PTEN/MMAC1 in primary bladder cancers. Oncogene 16, 3215-3218 (1998). [PubMed: 9671402]

121. Wang DS et al. Molecular analysis of PTEN and MXI1 in primary bladder carcinoma. Int. J. Cancer 88, 620-625 (2000). [PubMed: 11058880]

122. Puzio-Kuter AM et al. Inactivation of p53 and Pten promotes invasive bladder cancer. Genes Dev. 23, 675-680 (2009). [PubMed: 19261747]

123. van Nederveen FH et al. PTEN gene loss, butnot mutation, in benign and malignant phaeochromocytomas. J.Pathol. 209, 274-280 (2006). [PubMed: 16538614]

124. Gutierrez A et al. High frequency of PTEN, PI3K, and AKT abnormalities in T-cell acute lymphoblastic leukemia. Blood 114, 647-50 (2009). [PubMed: 19458356]

125. Silva A et al. PTEN posttranslational inactivation and hyperactivation of the PI3K/Akt pathway sustain primary T cell leukemia viability. J. Clin. Invest 118, 3762-3774 (2008). [PubMed: 18830414]

126. Gronbaek K, Zeuthen J, Guldberg P, Ralfkiaer E \& Hou-Jensen K Alterations of the MMAC1/ PTEN gene in lymphoid malignancies. Blood 91, 4388-4390 (1998). [PubMed: 9596690]

127. Sakai A, Thieblemont C, Wellmann A, Jaffe ES \& Raffeld M PTEN gene alterations in lymphoid neoplasms. Blood 92, 3410-3415 (1998). [PubMed: 9787181]

128. Scarisbrick JJ, Woolford AJ, Russell-Jones R \& Whittaker SJ Loss of heterozygosity on 10q and microsatellite instability in advanced stages of primary cutaneous T-cell lymphoma and possible association with homozygous deletion of PTEN. Blood 95, 2937-2942 (2000). [PubMed: 10779442]

129. Chen $\mathrm{M}$ et al. The deficiency of Akt1 is sufficient to suppress tumor development in Pten \pm mice. Genes Dev. 20, 1569-1574 (2006). [PubMed: 16778075]

130. Guertin DA et al. mTOR complex 2 is required for the development of prostate cancer induced by Pten loss in mice. Cancer Cell 15, 148-159 (2009). [PubMed: 19185849] 
131. Bayascas JR, Leslie NR, Parsons R, Fleming S \& Alessi DR Hypomorphic mutation of PDK1 suppresses tumorigenesis in PTEN+/- mice. Curr. Biol 15, 1839-1846 (2005). [PubMed: 16243031]

132. Podsypanina $\mathrm{K}$ et al. An inhibitor of mTOR reduces neoplasia and normalizes p70/S6 kinase activity in Pten $^{+/-}$mice. Proc. Natl Acad. Sci. USA 98, 10320-10325 (2001). [PubMed: 11504907]

133. Blando J et al. PTEN deficiency is fully penetrant for prostate adenocarcinoma in C57BL/6 mice via mTOR-dependent growth. Am. J. Pathol 174, 1869-1879 (2009). [PubMed: 19395652]

134. Huang $X$ et al. Important role of the LKB1-AMPK pathway in suppressing tumorigenesis in PTEN-deficient mice. Biochem. J 412, 211-221 (2008). [PubMed: 18387000]

135. Bissler JJ et al. Sirolimus for angiomyolipoma in tuberous sclerosis complex or lymphangioleiomyomatosis. N. Engl. J. Med 358, 140-151 (2008). [PubMed: 18184959]

136. Krueger DA et al. Everolimus for subependymal giant-cell astrocytomas in tuberous sclerosis. N. Engl. J. Med 363, 1801-1811 (2010). [PubMed: 21047224]

137. Marsh DJ et al. Rapamycin treatment for a child with germline PTEN mutation. Nature Clin. Pract. Oncol 5, 357-361 (2008). [PubMed: 18431376]

138. Mahalingam D, Sankhala K, Mita A, Giles FJ \& Mita MM Targeting the mTOR pathway using deforolimus in cancer therapy. Future Oncol. 5, 291-303 (2009). [PubMed: 19374536]

139. Easton JB \& Houghton PJ mTOR and cancer therapy. Oncogene 25, 6436-6446 (2006). [PubMed: 17041628]

140. Slomovitz BM et al. A phase 2 study of the oral mammalian target of rapamycin inhibitor, everolimus, in patients with recurrent endometrial carcinoma. Cancer 116, 5415-5419 (2010). [PubMed: 20681032]

141. Yuan R, Kay A, Berg WJ \& Lebwohl D Targeting tumorigenesis: development and use of mTOR inhibitors in cancer therapy. J. Hematol. Oncol 2, 45 (2009). [PubMed: 19860903]

142. Courtney KD, Corcoran RB \& Engelman JA The PI3K pathway as drug target in human cancer. J. Clin. Oncol 28, 1075-1083 (2010). [PubMed: 20085938]

143. Pal SK, Reckamp K, Yu H \& Figlin RA Akt inhibitors in clinical development for the treatment of cancer. Expert Opin. Investig. Drugs 19, 1355-1366 (2010).

144. Teresi RE et al. Increased PTEN expression due to transcriptional activation of PPAR $\gamma$ by Lovastatin and Rosiglitazone. Int. J. Cancer 118, 2390-2398 (2006). [PubMed: 16425225]

145. Liu X et al. Distinct roles for PTEN in prevention of T cell lymphoma and autoimmunity in mice. J. Clin. Invest 120, 2497-2507 (2010). [PubMed: 20516645]

146. Dedes KJ et al. PTEN deficiency in endometrioid endometrial adenocarcinomas predicts sensitivityto PARP inhibitors. Sci. Transl. Med 2, 53 ra75 (2010).

147. McEllin B et al. PTEN loss compromises homologous recombination repair in astrocytes: implications for glioblastoma therapy with temozolomide or poly(ADP-ribose) polymerase inhibitors. Cancer Res. 70, 5457-5464 (2010). [PubMed: 20530668]

148. Nagata $Y$ et al. PTEN activation contributes to tumor inhibition by trastuzumab, and loss of PTEN predicts trastuzumab resistance in patients. Cancer Cell 6, 117-127 (2004). [PubMed: 15324695]

149. Esteva FJ et al. PTEN, PIK3CA, p-AKT, and p-p70S6K status. association with trastuzumab response and survival in patients with HER2-positive metastatic breast cancer. Am. J. Pathol 177, 1647-1656 (2010). [PubMed: 20813970]

150. Ventura A et al. Restoration of p53 function leads to tumour regression in vivo. Nature 445, 661665 (2007). [PubMed: 17251932]

151. Junttila MR et al. Selective activation of p53-mediated tumour suppression in high-grade tumours. Nature 468, 567-571 (2010). [PubMed: 21107427]

152. Feldser DM et al. Stage-specific sensitivity to 553 restoration during lung cancer progression. Nature 468, 572-575 (2010). [PubMed: 21107428]

153. Freeman D et al. Genetic background controls tumor development in PTEN-deficient mice. Cancer Res. 66, 6492-6496 (2006). [PubMed: 16818619] 
154. Engel C et al. Association of the Variants CASP8 D302H and CASP10 V410I with Breast and Ovarian Cancer Risk in BRCA1 and BRCA2 Mutation Carriers. Cancer Epidemiol. Biomarkers Prev. 19, 2859-2868 (2010). [PubMed: 20978178]

155. Trimboli AJ et al. Pten in stromal fibroblasts suppresses mammary epithelial tumours. Nature 461, 1084-1091 (2009). [PubMed: 19847259]

156. Hamada $\mathrm{K}$ et al. The PTEN/PI3K pathway governs normal vascular development and tumor angiogenesis. Genes Dev. 19, 2054-2065 (2005). [PubMed: 16107612]

157. Groszer $\mathrm{M}$ et al. Negative regulation of neural stem/progenitor cell proliferation by the Pten tumor suppressor gene in vivo. Science 294, 2186-2189 (2001). [PubMed: 11691952]

158. Gregorian $\mathrm{C}$ et al. Pten deletion in adult neural stem/progenitor cells enhances constitutive neurogenesis. J. Neurosci 29, 1874-1886 (2009). [PubMed: 19211894]

159. Wang $\mathrm{S}$ et al. Pten deletion leads to the expansion of a prostatic stem/progenitor cell subpopulation and tumor initiation. Proc. Natl Acad. Sci. USA 103, 1480-1485 (2006). [PubMed: 16432235]

160. Korsten H, Ziel-van der Made A, Ma X,van der Kwast T \& Trapman J Accumulating progenitor cells in the luminal epithelial cell layer are candidate tumor initiating cells in a Pten knockout mouse prostate cancer model. PLoS ONE 4, e5662 (2009). [PubMed: 19461893]

161. Mulholland DJ et al. Lin ${ }^{-} \mathrm{Sca}-1^{+} \mathrm{CD} 49 \mathrm{f}^{\text {high }}$ stem/progenitors are tumor-initiating cells in the Pten-null prostate cancer model. Cancer Res. 69, 8555-8562 (2009). [PubMed: 19887604]

162. Yilmaz $\mathrm{OH}$ et al. Pten dependence distinguishes haematopoietic stem cells from leukaemiainitiating cells. Nature 441, 475-482 (2006). [PubMed: 16598206]

163. Zhang J et al. PTEN maintains haematopoietic stem cells and acts in lineage choice and leukaemia prevention. Nature 441, 518-522 (2006). [PubMed: 16633340]

164. Peng $\mathrm{C}$ et al. PTEN is a tumor suppressor in CML stem cells and BCR-ABL-induced leukemias in mice. Blood 115, 626-635 (2010). [PubMed: 19965668]

165. Furnari FB, Huang HJ \& Cavenee WK The phosphoinositol phosphatase activity of PTEN mediates a serum-sensitive G1 growth arrest in glioma cells. Cancer Res. 58, 5002-5008 (1998). [PubMed: 9823298]

166. Lee JO et al. Crystal structure of the PTEN tumor suppressor: implications for its phosphoinositide phosphatase activity and membrane association. Cell 99, 323-334 (1999). [PubMed: 10555148]

167. Georgescu MM et al. Stabilization and productive positioning roles of the $\mathrm{C} 2$ domain of PTEN tumor suppressor. Cancer Res. 60, 7033-7038 (2000). [PubMed: 11156408]

168. Adey NB et al. Threonine phosphorylation of the MMAC1/PTEN PDZ binding domain both inhibits and stimulates PDZ binding. Cancer Res. 60, 35-37 (2000). [PubMed: 10646847]

169. Georgescu MM, Kirsch KH, Akagi T, Shishido T \& Hanafusa H The tumor-suppressor activity of PTEN is regulated by its carboxyl-terminal region. Proc. Natl Acad. Sci. USA 96, 10182-10187 (1999). [PubMed: 10468583]

170. Vanhaesebroeck B \& Alessi DR The PI3K-PDK1 connection: more than just a road to PKB. Biochem. J 346, 561-576 (2000). [PubMed: 10698680]

171. Hynes NE \& MacDonald G ErbB receptors and signaling pathways in cancer. Curr. Opin. Cell Biol. 21, 177-184 (2009). [PubMed: 19208461]

172. Dowling RJ, Topisirovic I, Fonseca BD \& Sonenberg N Dissecting the role of mTOR: lessons from mTOR inhibitors. Biochim. Biophys. Acta 1804, 433-439 (2010). [PubMed: 20005306]

173. Loewith $\mathrm{R}$ et al. Two TOR complexes, only oneof which is rapamycin sensitive, have distinct rolesin cell growth control. Mol. Cell 10, 457-468 (2002). [PubMed: 12408816]

174. O'Reilly KE et al. mTOR inhibition induces upstream receptor tyrosine kinase signaling and activates Akt. Cancer Res. 66, 1500-1508 (2006). [PubMed: 16452206]

175. Sarbassov DD, Guertin DA, Ali SM \& Sabatini DM Phosphorylation and regulation of Akt/PKB by the rictor-mTOR complex. Science 307, 1098-1101 (2005). [PubMed: 15718470]

176. Edelman G A phase I dose-escalation study of XL147 (SAR245408), a PI3K inhibitor administered orally to patients (pts) with advanced malignancies. Am. Soc. Clin. Oncol. Abstr 28, 3004 (2010). 
177. Von Hoff DD et al. A first-in-human phase I studyto evaluate the pan-PI3K inhibitor GDC-0941 administered QD or BID in patients with advanced solid tumors. Am. Soc. Clin. Oncol. Abstr 28, 2541 (2010).

178. O'Brien C et al. Predictive biomarkers of sensitivity to the phosphatidylinositol 3' kinase inhibitor GDC-0941 in breast cancer preclinical models. Clin. Cancer Res. 16, 3670-3683 (2010). [PubMed: 20453058]

179. Floris G et al. Activity of GDC-0941, an inhibitor of phosphoinositol 3 kinase (PI3K), in gastrointestinal stromal tumor (GIST) xenograft and duration of response after discontinuation of treatment in combination with imatinib. Am. Soc. Clin. Oncol. Abstr 28, 10020 (2010).

180. Jimeno A et al. Final results from a phase I, dose-escalation study of PX-866, an irreversible, panisoform inhibitor of PI3 kinase. Am. Soc. Clin. Oncol. Abstr 28, 3089 (2010).

181. Le Cras TD et al. Inhibition of PI3K by PX-866 prevents transforming growth factor-a-induced pulmonary fibrosis. Am. J. Pathol 176, 679-686 (2010). [PubMed: 20042669]

182. Baselga J et al. A first-in-human phase I study of BKM120, an oral pan-class I PI3K inhibitor, in patients (pts) with advanced solid tumors. Am. Soc. Clin. Oncol. Abstr 28, 3003 (2010).

183. Buonamici $\mathrm{S}$ et al. Interfering with resistance to smoothened antagonists by inhibition of the PI3K pathway in medulloblastoma. Sci. Transl. Med 2, 51 ra70 (2010).

184. Furman RR et al. Interim results from a phase I study of CAL-101, a selective oral inhibitor of phosphatidylinositol 3-kinase p110d isoform, in patients with relapsed or refractory hematologic malignancies. Am. Soc. Clin. Oncol. Abstr 28, 3032 (2010).

185. Burris $\mathrm{H}$ et al. First-in-human phase I study of the oral PI3K inhibitor BEZ235 in patients (pts) with advanced solid tumors. Am. Soc. Clin. Oncol. Abstr 28, 3005 (2010).

186. Chiorean EG et al. Phase I evaluation of SF1126, a vascular targeted PI3K inhibitor, administered twice weekly IV in patients with refractory solid tumors. Am. Soc. Clin. Oncol. Abstr 27, 2558 (2009).

187. Garlich JR et al. A vascular targeted pan phosphoinositide 3-kinase inhibitor prodrug, SF1126, with antitumor and antiangiogenic activity. Cancer Res. 68, 206-215 (2008). [PubMed: 18172313]

188. Dolly S et al. A first-in-human, phase 1 study to evaluate the dual PI3K/mTOR inhibitor GDC-0980 administered QD in patients with advanced solid tumors or non-Hodgkin's lymphoma. Am. Soc. Clin. Oncol. Abstr 28, 3079 (2010).

189. Brana I et al. A phase I dose-escalation study of the safety, pharmacokinetics (PK), and pharmacodynamics of XL765 (SAR245409), a PI3K/TORC1/TORC2 inhibitor administered orally to patients (pts) with advanced malignancies. Am. Soc. Clin. Oncol. Abstr 28, 3030 (2010).

190. Prasad G et al. Inhibition of PI3K/mTOR pathways in glioblastoma and implications for combination therapy with temozolomide. Neuro Oncol 1122011 (doi:10.1093/neuonc/noq193).

191. Mallon R et al. Antitumor efficacy profile of PKI-402, a dual phosphatidylinositol 3-kinase/ mammalian target of rapamycin inhibitor. Mol. Cancer Ther. 9, 976-984 (2010). [PubMed: 20371716]

192. Venkatesan AM et al. Bis(morpholino-1,3,5-triazine) derivatives: potent adenosine 5'triphosphate competitive phosphatidylinositol-3-kinase/mammalian target of rapamycin inhibitors: discovery of compound 26 (PKI-587), a highly efficacious dual inhibitor. J. Med. Chem 53, 2636-2645 (2010). [PubMed: 20166697]

193. Motzer RJ et al. Efficacy of everolimus in advanced renal cell carcinoma: a double-blind, randomised, placebo-controlled phase III trial. Lancet 372, 449-456 (2008). [PubMed: 18653228]

194. Hudes $\mathrm{G}$ et al. Temsirolimus, interferon alfa, or both for advanced renal-cell carcinoma. N. Engl. J. Med 356, 2271-2281 (2007). [PubMed: 17538086]

195. Yao JC et al. Everolimus for advanced pancreatic neuroendocrine tumors. N. Engl. J. Med 364, 514-523 (2011). [PubMed: 21306238]

196. Dancey J mTOR signaling and drug developmentin cancer. Nature Rev. Clin. Oncol 7, 209-219 (2010). [PubMed: 20234352] 
197. Squarize CH, Castilho RM \& Gutkind JS Chemoprevention and treatment of experimental Cowden's disease by mTOR inhibition with rapamycin. Cancer Res. 68, 7066-7072 (2008). [PubMed: 18757421]

198. Zhang W et al. Inhibition of tumor growth progression by antiandrogens and mTOR inhibitor in a Pten-deficient mouse model of prostate cancer. Cancer Res. 69, 7466-7472 (2009). [PubMed: 19738074]

199. Granville CA et al. Identification of a highly effective rapamycin schedule that markedly reduces the size, multiplicity, and phenotypic progression of tobacco carcinogen-induced murine lung tumors. Clin. Cancer Res. 13, 2281-2289 (2007). [PubMed: 17404113]

200. Stelzer MK et al. Rapamycin inhibits anal carcinogenesis in two preclinical animal models. Cancer Prev. Res 3, 1542-1551 (2010).

201. Cen O \& Longnecker R Rapamycin reverses splenomegaly and inhibits tumor development in a transgenic model of Epstein-Barr Virus-related Burkitt's lymphoma. Mol. Cancer Ther. 311 2011 (doi:10.1158/1535-7163.MCT-10-0833).

202. Seager CM et al. Intravesical delivery of rapamycin suppresses tumorigenesis in a mouse model of progressive bladder cancer. Cancer Prev. Res 2, 1008-1014 (2009).

203. Namba R et al. Rapamycin inhibits growth of premalignant and malignant mammary lesions in a mouse model of ductal carcinoma in situ. Clin. Cancer Res. 12, 2613-2621 (2006). [PubMed: 16638874]

204. Diegel CR, Cho KR, El-Naggar AK, Williams BO \& Lindvall C Mammalian target of rapamycindependent acinar cell neoplasia after inactivation of Apc and Pten in the mousesalivary gland: implications for human aciniccell carcinoma. Cancer Res. 70, 9143-9152 (2010). [PubMed: 21062985]

205. Chiu CW, Nozawa H \& Hanahan D Survival benefit with proapoptotic molecular and pathologic responses from dual targeting of mammalian target of rapamycin and epidermal growth factor receptor in a preclinical model of pancreatic neuroendocrine carcinogenesis. J. Clin. Oncol 28, 4425-4433 (2010). [PubMed: 20823411]

206. Chresta CM et al. AZD8055 is a potent, selective, and orally bioavailable ATP-competitive mammalian target of rapamycin kinase inhibitor with in vitro and in vivo antitumor activity. Cancer Res. 70, 288-298 (2010). [PubMed: 20028854]

207. Richards DA et al. Final results of a randomized phase II study of perifosine in combination with capecitabine (P-CAP) versus placebo plus capecitabine (CAP) in patients (pts) withsecond- or third-line metastatic colorectal cancer (mCRC). Am. Soc. Clin. Oncol. Abstr 28, 3531 (2010).

208. Hideshima T et al. Perifosine, an oral bioactive novel alkylphospholipid, inhibits Akt and induces in vitro and in vivo cytotoxicity in human multiple myeloma cells. Blood 107, 4053-4062 (2006). [PubMed: 16418332]

209. Li Z, Tan F, Liewehr DJ, Steinberg SM \& Thiele CJ In vitro and in vivo inhibition of neuroblastoma tumor cell growth by AKT inhibitor perifosine. J. Natl Cancer Inst. 102, 758-770 (2010). [PubMed: 20463309]

210. Tolcher AW et al. A phase I study of MK-2206, an oral potent allosteric Akt inhibitor (Akti), in patients (pts) with advanced solid tumor (ST). Am. Soc. Clin. Oncol. Abstr 27, 3503 (2009).

211. Hirai $\mathrm{H}$ et al. MK-2206, an allosteric Akt inhibitor, enhances antitumor efficacy by standard chemotherapeutic agents or molecular targeted drugs in vitro and in vivo. Mol. Cancer Ther. 9, 1956-1967 (2010). [PubMed: 20571069]

212. Mao JH et al. Genetic interactions between Pten and p53 in radiation-induced lymphoma development. Oncogene 22, 8379-8385 (2003). [PubMed: 14627978]

213. Birck A, Ahrenkiel V, Zeuthen J, Hou-Jensen K \& Guldberg P Mutation and allelic loss of the PTEN/MMAC1 gene in primary and metastatic melanoma biopsies. J. Invest. Dermatol 114, 277-280 (2000). [PubMed: 10651986]

214. Celebi JT, Shendrik I, Silvers DN \& Peacocke M Identification of PTEN mutations in metastatic melanoma specimens. J. Med. Genet 37, 653-657 (2000). [PubMed: 10978354]

215. Rahman MA et al. Impact of PTEN expression on the outcome of hepatitis C virus-positive cirrhotic hepatocellular carcinoma patients: possible relationship with COX II and inducible nitric oxide synthase. Int. J. Cancer 100, 152-157 (2002). [PubMed: 12115563] 
216. Chen S et al. VHL and PTEN loss coordinate to promote mouse liver vascular lesions. Angiogenesis 13, 59-69 (2010). [PubMed: 20221685]

217. Shao J, Washington MK, Saxena R \& Sheng H Heterozygous disruption of the PTEN promotes intestinal neoplasia in APCmin/+ mouse: roles of osteopontin. Carcinogenesis 28, 2476-2483 (2007). [PubMed: 17693663]

218. Zhou XP et al. PTEN mutational spectra, expression levels, and subcellular localization in microsatellite stable and unstable colorectal cancers. Am. J. Pathol 161, 439-447 (2002). [PubMed: 12163369]

219. Heald B et al. Frequent gastrointestinal polyps and colorectal adenocarcinomas in a prospective series of PTEN mutation carriers. Gastroenterology 139, 1927-1933 (2010). [PubMed: 20600018] 


\section{At a glance}

- $\quad$ PTEN hamartoma tumour syndrome (PHTS) is a group of syndromes characterized by benign growths and a high risk for cancers of the breast, endometrium and thyroid. Cowden syndrome is the best characterized of these and $85 \%$ of patients have germline PTEN mutations. The range of abnormalities in patients with PHTS varies from patient to patient.

- $\quad$ Somatic PTEN mutations and deletions, and inactivation of PTEN by methylation or microRNA silencing, are common in multiple tumour types. These include the classical PHTS-associated tumours like breast, endometrium and thyroid, but also tumours of the central nervous system, prostate, lung, pancreas, liver and adrenal glands, as well as melanoma, leukaemia and lymphoma.

- $\quad$ Mouse models of Cowden syndrome, in which a single allele of Pten is deleted or mutated, exhibit characteristic Cowden syndrome phenotypes. Tumour types are very much dependent on the genetic background of the mice suggesting that there may be genetic risk factors for PHTS penetrance in humans.

- Tissue-specific deletion of Pten in mice can lead to rapid, slow or no tumours, depending on the tissue type. In some cases, tissue-specific Pten deletion can cooperate with other genetic alterations to enhance tumorigenesis. These mouse models have validated mutation or loss of PTEN as an aetiological factor in similar human tumours.

- $\quad$ PTEN is a lipid phosphatase that acts as a negative regulator of the PI3KAKT-mTOR pathway, which is an important regulator of cell growth and survival. As such, pharmacological inhibition of this pathway may be exploited for therapy of tumours with altered PTEN, or for tumour prevention in patients with PHTS. 


\section{Box 1 |}

\section{What determines tumour risk in Cowden syndrome?}

A limited number of mouse studies suggest that both the type of germline Pten mutation and the genetic background can affect risk for specific tumour types. Comparison of three different Cowden syndrome-specific Pten mutations in the same mouse strain indicated that specific Pten mutations may contribute to risk for specific tumour types ${ }^{153}$. In this study, specific mutations altered the relative frequency of uterus, prostate, thyroid and mammary neoplasms but did not alter the range of tumour types. These types of studies may help to stratify PTEN mutations in patients with Cowden syndrome in order to identify those at the highest risk for specific tumour types. Conversely, studies using Pten ${ }^{+/-}$and $P t e n \Delta^{5 /+}$ (deletion of exon 5) mice indicate that genetic background is also a very strong determinant of tumour susceptibility in mice ${ }^{153}$. Given the diversity of the human genome, identification of risk factors that contribute to tumour susceptibility in Cowden syndrome might help to predict the risk of specific tumours in this population. For example, polymorphisms in caspase 8 have been identified as risk factors for breast and ovarian cancers in tumour-prone $B R C A 1$ mutation carriers ${ }^{154}$. Naturally occuring polymorphisms within $P T E N$ itself are found at a disproportionately high rate in patients with Cowden syndrome, even in the absence of apparent PTEN mutation, suggesting that certain PTENhaplotypes might function as risk-modifying factors ${ }^{20}$. However, given the number of different $P T E N$ mutations in Cowden syndrome that may also affect risk even large genome-wide association studies (GWAS) might have trouble detecting additional risk loci. Identification of risk-modifying loci in inbred mouse models for Cowden syndrome could inform more targeted searches for human risk factors. In addition, risk factors for Cowden syndrome tumours might also prove to be risk factors for PTENmutant sporadic tumours. However, in Cowden syndrome, PTEN alteration in nontumour cell types, such as stroma, endothelial and immune cells, may also contribute to increased tumour risk ${ }^{46,155,156}$ possibly exacerbating other general risk factors. 


\section{Box 2}

\section{The role of PTEN in the maintenance of tissue and cancer stem cells}

The fact that loss of PTEN can cause or contribute to tumorigenesis in several tissues suggests that PTEN might control tumour-initiating cells. In fact, Pten deletion can increase the self-renewal capacity of normal stem cells and increase the number of putative tumour-initiating cells. In neural stem cells, Pten deletion increases self-renewal capacity ${ }^{157}$, which was further augmented by co-deletion of Trp53 (REF. 86). Pten deletion in the adult subependymal zone also increased neural stem cell self-renewal, leading to enhanced olfactory bulb mass and enhanced olfactory function ${ }^{158}$. Increased stem and progenitor cells have been reported in Pten-deficient prostate, lung, intestinal and pancreatic tissues before tumour formation ${ }^{49,114,159-161}$. In both haematopoietic cells and melanocytes, Pten deletion leads to normal stem cell exhaustion ${ }^{102,162,163}$, but paradoxically, in haematopoietic cancer stem cells, Pten deletion leads to unlimited expansion ${ }^{162,164}$. Although still an emerging concept, the role of tumour-initiating cells and control by PTEN is an area of intense investigation. 


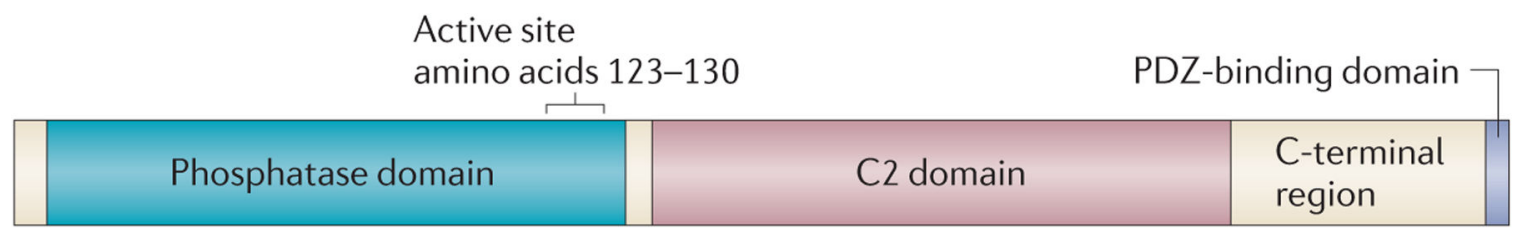

Figure $1 \mid$. Schematic of the PTEN protein.

PTEN contains two key domains that are required for its tumour suppressor function; the phosphatase (catalytic) domain (amino acids 14-185) ${ }^{165}$ with an active site included within the residues 123 and 130 (REF. 166), and the C2 (lipid membrane-binding) domain (amino acids 190-350) ${ }^{167}$. The importance of other domains such as the PDZ-binding domain (in grey; amino acids 401-403) ${ }^{168}$, which binds proteins containing PDZ domains, and the carboxy-terminal region (amino acids 351-400), which contains PEST sequences and may contribute to protein stability and activity ${ }^{169}$, is less defined in the tumour suppressor functions of PTEN. 


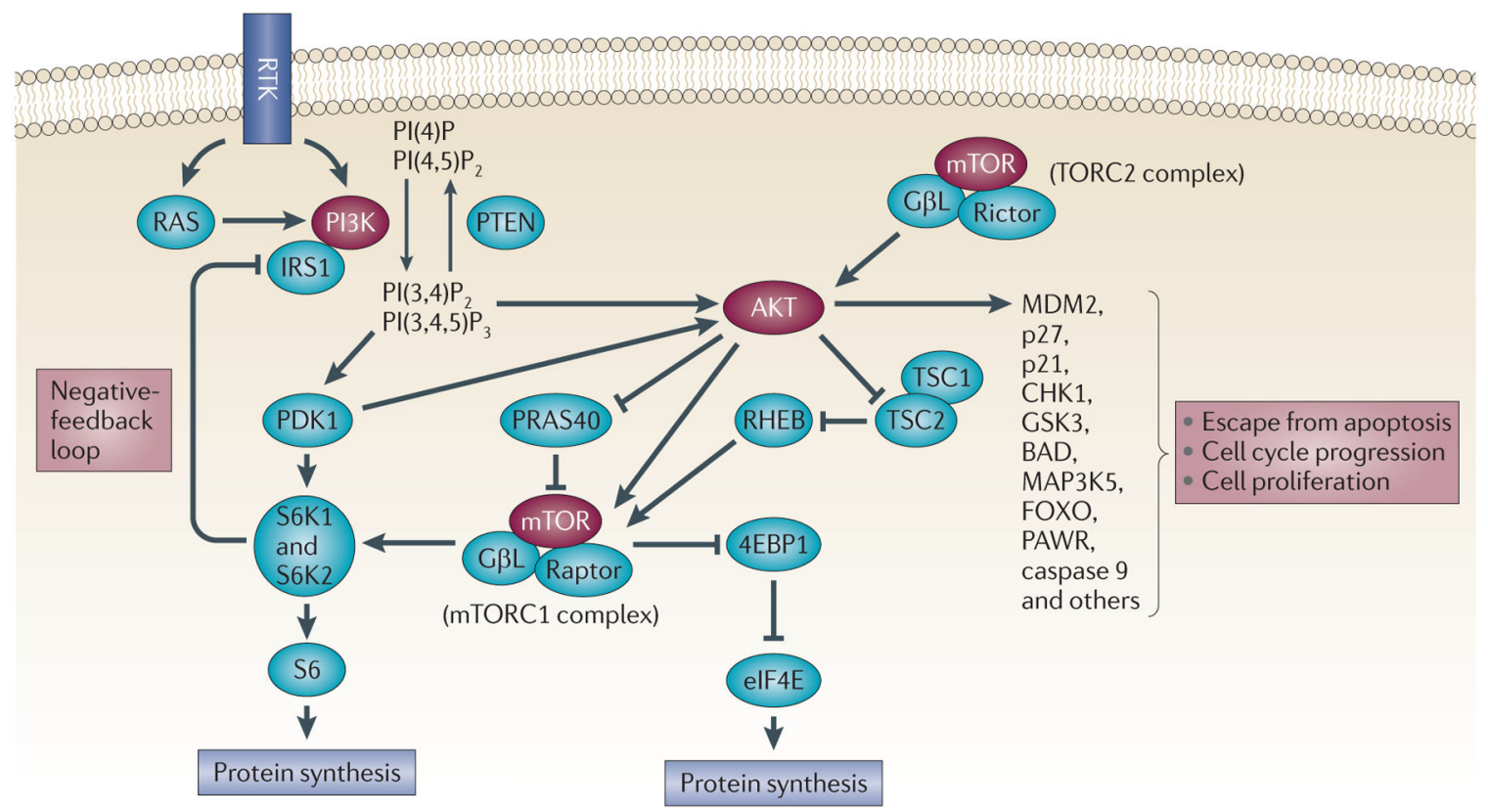

Figure 2 |. Canonical PTEN-PI3K-AKT-mTOR pathway.

PTEN opposes PI3K function, leading to inactivation of AKT crucial downstream target ${ }^{1}$. When PTEN activity is decreased or absent, products of PI3K activate AKT through the activation of its upstream kinase phosphoinositide-dependent kinase 1 (PDK1; encoded by $P D P K 1)^{170}$. Other upstream regulators of the pathway include receptor tyrosine kinases (RTKs) such as ERBB2 and epidermal growth factor receptor (EGFR) that are important in breast and lung cancer, respectively (reviewed in REF. 171). Important downstream targets of AKT (such as p27, p21, FOXO and PAWR (also known as PAR4)) are involved in multiple functions that are crucial for tumour cell growth and survival (reviewed in REF. 8). mTOR activity is also increased when PTEN activity is lost, and mTOR itself has important targets, including AKT, as well as proteins required for protein translation such as ribosomal protein S6 kinase (S6K; encoded by RPS6KB1 and TPS6KB2) and eukaryotic initiation factor $4 \mathrm{E}$ binding protein (4EBP1; encoded by EIF4EBP1) ${ }^{172}$. mTOR exists in two different protein complexes, TORC1 and TORC2 (REF. 173). Inhibitors of TORC1 by drugs such as rapamycin can activate AKT by deactivating a negative-feedback loop mediated by S6K and insulin receptor substrate 1 (IRS1) ${ }^{174,175}$. Proteins that can be targeted by drugs (as outlined in TABLE 2) are indicated in red. BAD, BCL-2-associated agonist of cell death; GSK3, glycogen synthase kinase 3; MAP3K5, apoptosis signal regulator kinase 1. 


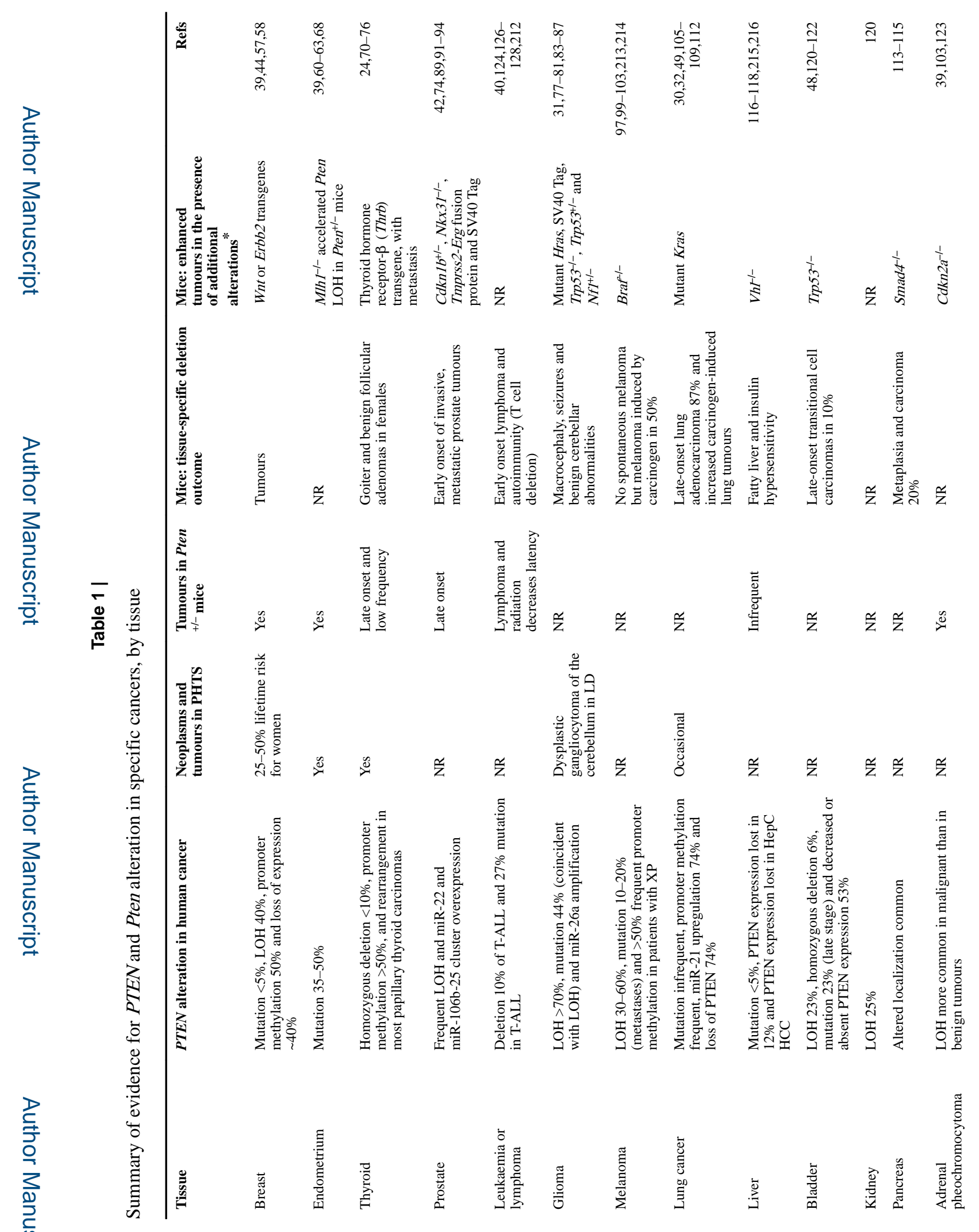

Nat Rev Cancer. Author manuscript; available in PMC 2020 January 07. 
Hollander et al.

Page 29

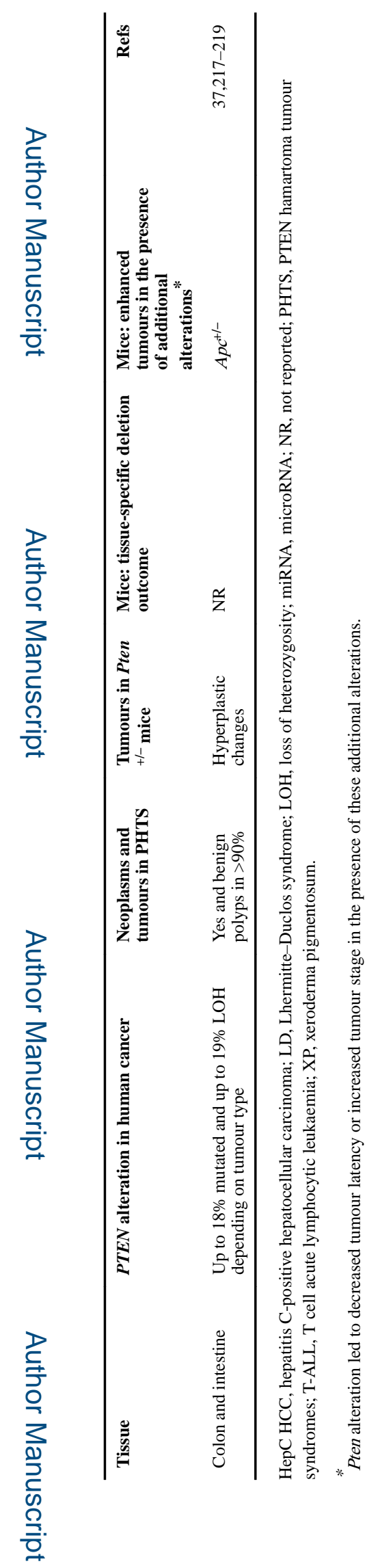

Nat Rev Cancer. Author manuscript; available in PMC 2020 January 07. 


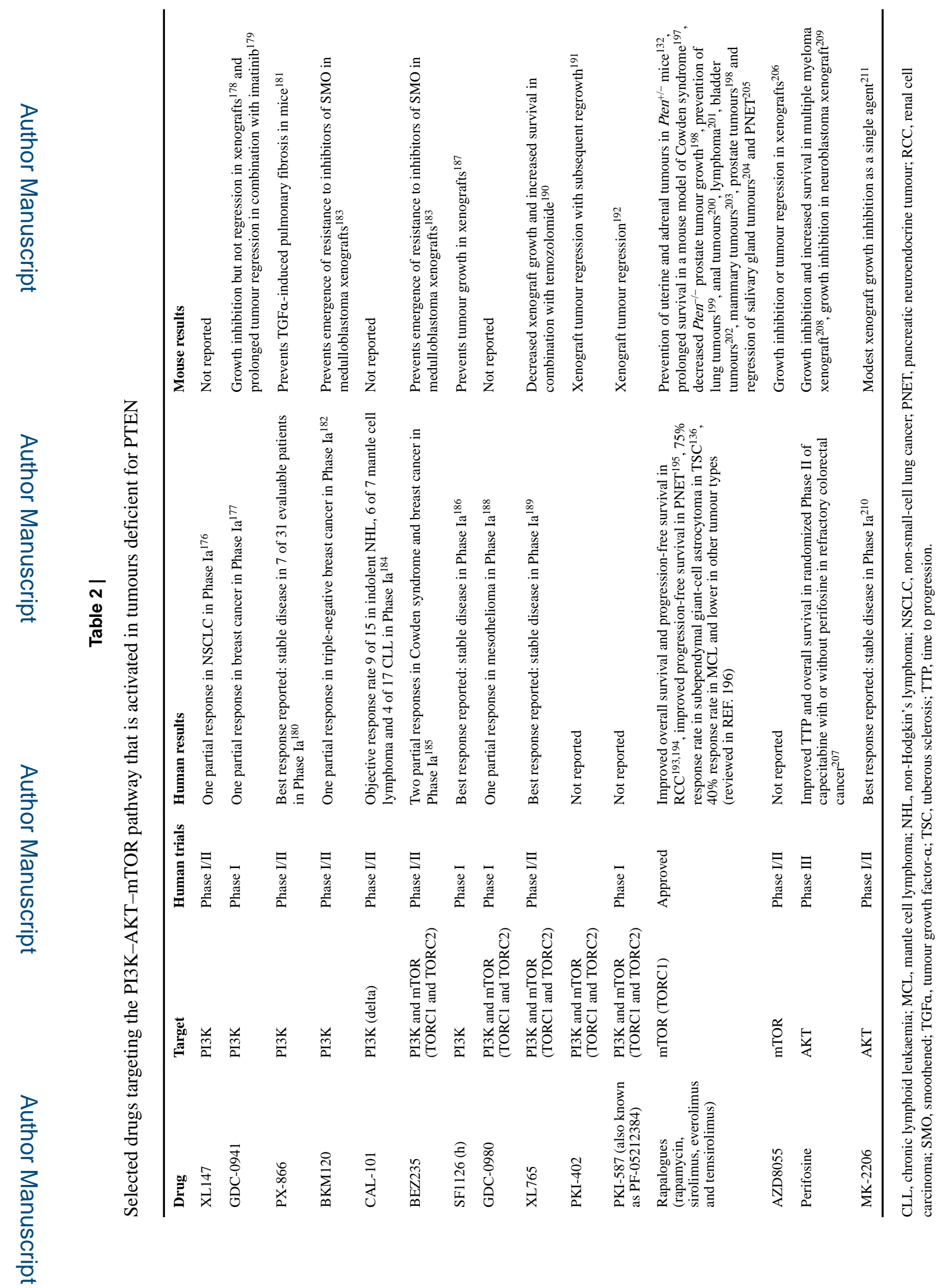

Nat Rev Cancer. Author manuscript; available in PMC 2020 January 07. 